\title{
The Upcycling and Reconstruction of Garments and Fabrics
}

\author{
Yuan Zhi \\ Department of Art and Design, Northumbria University, Newcastle, UK \\ Email: zhiyuan1217ys@163.com
}

How to cite this paper: Zhi, Y. (2022). The Upcycling and Reconstruction of Garments and Fabrics. Art and Design Review, 10, $72-102$.

https://doi.org/10.4236/adr.2022.101007

Received: December 10, 2021

Accepted: January 25, 2022

Published: January 28, 2022

Copyright $\odot 2022$ by author(s) and Scientific Research Publishing Inc. This work is licensed under the Creative Commons Attribution International License (CC BY 4.0).

http://creativecommons.org/licenses/by/4.0/

\begin{abstract}
The reconstruction of clothing and fabrics is also called the "secondary treatment of fabrics". It usually challenges the reorganization of the original form, transforms the original single fabric style, displays new effects, and performs more unique definitions. Redesign requires minimizing its negative impact while exploring its more considerable positive contribution to society. Designers need to act as a role of "interpreter". They translate the original products into more responsible ones, not only to be innovative but also to avoid harming the environment. In the perspective of recycling design, I will re-define different substances, adopt the secondary design of fabrics and the re-transformation of waste clothing. It is critical to emphasize that products should be natural and eco-friendly.
\end{abstract}

\section{Keywords}

Fashion Design, Upcycling and Reconstruction of Garments and Fabrics, Eco-Friendly Clothes Design, Retransformation of Waste Clothing

\section{Background}

The rapid production of cheap clothing has aroused public controversy in recent years. The fashion industry accelerated its pace of production and fabrication to satisfy the enlarging demand for "trendy" pieces within society. Unfortunately, sustainability has been neglected gradually (Gam, 2011). Some fashion designers and manufacturers have started to seek a balance between high fashion and sustainability. They want to recycle the "out time" pieces while producing less waste with fewer resources applied (Gam, 2011).

It is undeniable that the fashion industry is eager to explore a way to realize the goal. They need "fundamental redesign" (Francois, 2019). It dawns light on the minds of people who look forward to the new "make-recycle-make" circular 
mode.

This framework sets an excellent example for the fashion industry (see Figure 1). It abandons the traditional "sacrificing resources and environment to make money" mindset. Instead, waste can be re-used; the natural environment can be regenerated. It is a "win-win" idea (Francois, 2019). The innovation of a business model cannot conflict with the designer's design concept. If a designer picks a renewable and eco-friendly material, the circular of recycling will be formed from the beginning (Francois, 2019).

\section{Personal Development Plan}

\subsection{PDP}

After the background research, it is confirmed that the themes and ideas formed through this semester can be implemented. The consultation of relevant materials to understand the combination and deconstruction of clothing and the knowledge of cutting and reinventing clothing are fundamental. To achieve this goal, I need to record daily processes, which is the discovery of all kinds of materials that can be applied to clothing from daily life, including patterns, fabrics, objects of different materials, etc.

In addition, it can also help me to discover more exciting designs in the upcoming exploration. Therefore, I made a personal plan for my future design exploration (see Figure 2).

\subsection{Aim and Objective}

The topic of "reorganization and reconstruction of clothing" has aroused great attention in the contemporary society (see Loscialpo, 2014; Larsen, 2011). It is also a new understanding of the conception of fashion design.

Creating a new textiles economy

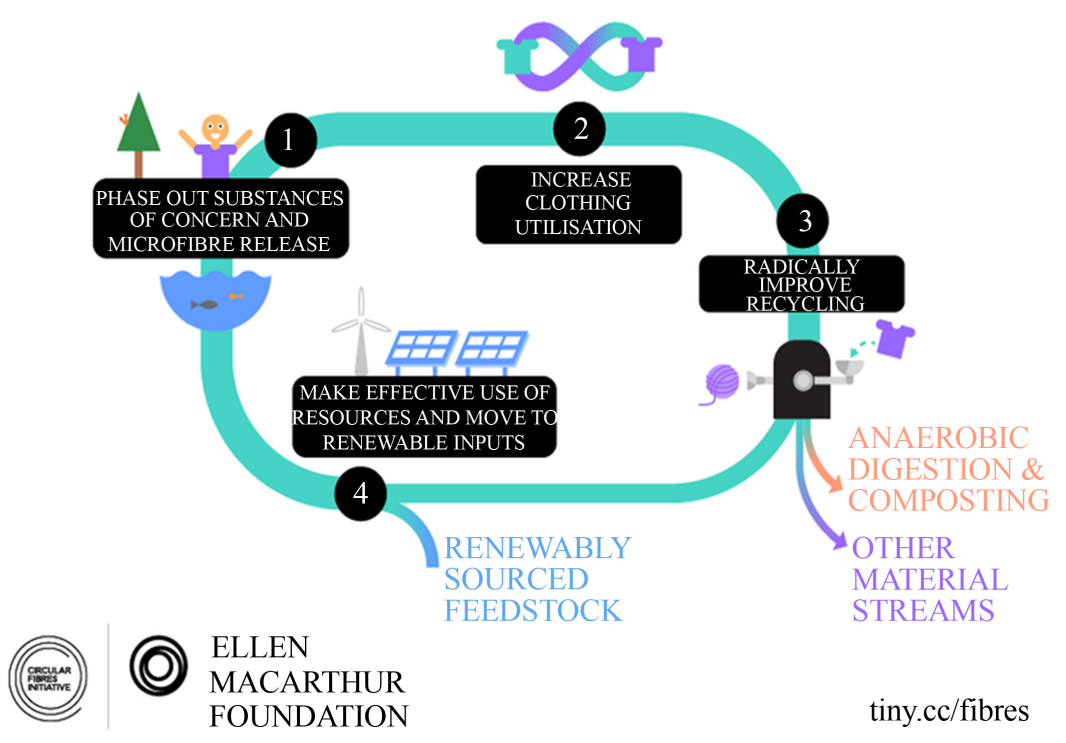

Figure 1. Creating a new textile economy. 
Short-time

Consult relevant materials to understand the combination principle and deconstruction of clothing. Learn to cut and reinvent clothing.

Long-time

Establish a clothing brand. First of all, intern work in the fashion design industry and accumulate work experience. Second, learn relevant knowledge of brand management.

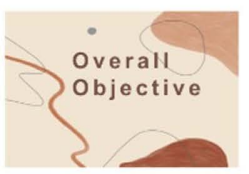

- Learn the structure of clothing, different ways of cutting clothing, and the culture of clothing deconstruction.

- Discover all kinds of materials that can be applied to clothing from daily life, including patterns, fabrics, objects of different materials, etc.

- A deeper understanding of what is sustainable clothing design.

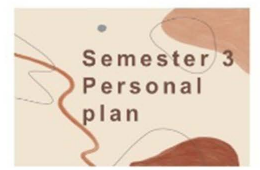

- Fashion Design

- Graphic Design

- Accessories design

- Brand Management

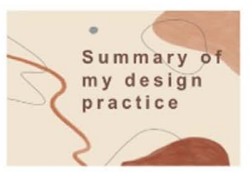

- Sewing techniques

- A way to combine objects of different materials with a piece of clothing.

- Selection and identification of clothing fabrics.

- fabric reconstruction and reaction textile.

Brand Management

\section{- Have studied fashion design for four years and have a certain understanding of fashion design. \\ - Willing to listen to others' suggestions and have fast learning ability. \\ - Have some design experience in the market. \\ - There is always a lot of imagination and inspiration for design.}

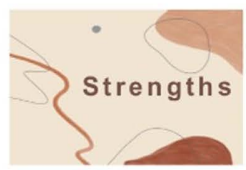

- Critical literature review

- Talk to tutor

- Talk to people in the fashion design industry.

- Conduct research on different sustainable apparel brands around the world and visit these studios to learn.
- Not familiar with marketing and brand management.

- A bit weak in English. Do not understand business strategy.

- Have a little bit of procrastination.

- Not good at designing brand logos.

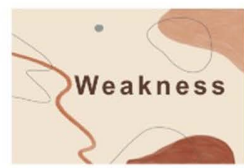

- The fashion design industry have an indispensable role in the global.

- Recycling and reorganization of clothing is already a very popular trend in the world, and it also means that sustainable design is gradually replacing the original clothing.

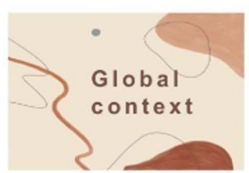

Figure 2. Personal plan (short-time and long-time plan).

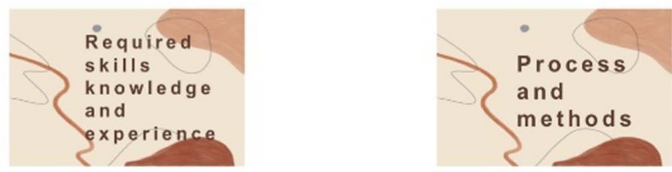

The recycling and recreation of clothing also contribute to the environment, which is humanized and people-oriented. According to the background research, this topic is meaningful and can offer people a brand new recognition and understanding of recycling and reconstruction. 
The primary purpose of this semester's exploration is to transform waste clothing through recycling and reconstruction, form a new piece of clothing or a design product with an artistic appreciation. During this period, two main objectives were set up for the project: research on fabric recreation and stitching of objects of different materials. Fabric design is an important learning goal. Considering its raw materials are mainly from waste clothing, it is of great help to design new garments. After obtaining a specific ability to reconstruct the textile, more innovative applications can be used in other waste objects in daily life.

\subsection{Time Plan}

Before the start of a project, detailed planning is critical. I divided my process into three parts. At first, I will conduct preliminary research and material collection. In the second part, I will conduct more in-depth research and design. The final stage will be applied to the final design. I made a schedule using the Gantt Chart to illustrate my plan clearly (presented in Figure 3 ).

\section{Research \& Practice}

\subsection{Literature Review}

\subsubsection{In-Depth Study of Fabric Reconstruction}

Fabric reconstruction offers a second life to the original fabric. Its primary performance lies in the creative fabric texture. The aesthetic visualization of fabric texture is displayed mainly by the arrangement and aggregation of unit elements. This organization can be regular or erratic (Libo, 2019).

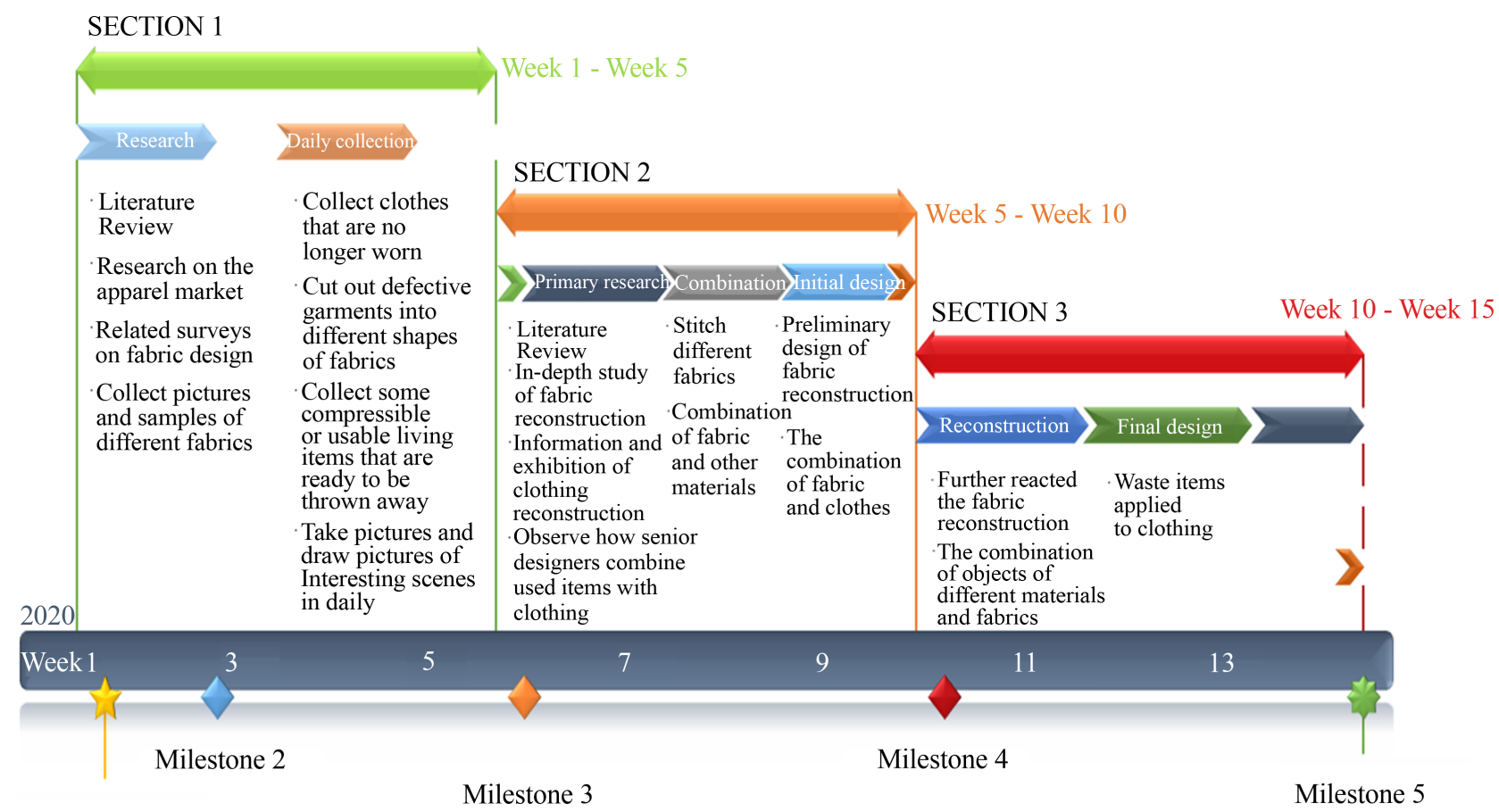

Milestone 1

Figure 3. Gantt (https://www.officetimeline.com/gantt-chart/templates/powerpoint-gantt). 
Reconstructed fabrics need to consider their practicality and their aesthetic performance. In addition, their future potential should be evaluated simultaneously (Libo, 2019).

The recreation of art in costume design has become an important method to increase more added value to clothing products. Secondary costume design-wise, "fabric reengineering" can also be applied. It refers to the processing and transformation of ready-made fabric. These two methods can maintain the artistic charm of clothing while meeting the fashion industry's standards (Jun \& Yueming, 2015).

The reconstruction of fabric is commonly discussed these days in the fashion industry. Its techniques are also varied-making folds, cutting hollows, sewing and attaching, and weaving and twisting. Because of its diversity, reconstructed fabrics are welcome in clothing fabrication, jewelry design, and other forms of artistic creativity (Libo, 2019).

Using a combination of fabrics to create gradually became fashion design with a breakthrough, and the value of the clothing products enhanced. The essential means of the combination of fabric is the fabric itself between the fabrics, and between a variety of fabrics to reflect the diversity of fabrics to express strengthen the innovation of clothing on the vision express the aesthetic effect. Rich and complex re-invention of fabric uses traditional and high-tech means of shape again shows its rich connotation in the costume design (Yueming, 2015).

The combination and recreation of fabrics have gradually become a groundbreaking trend in fashion design, which is crucial for adding value to clothing. Various fabrics can be aggregated to add new feelings to the clothes. I have also collected pictures and different fabrics samples (see Figure 4 and Figure 5).
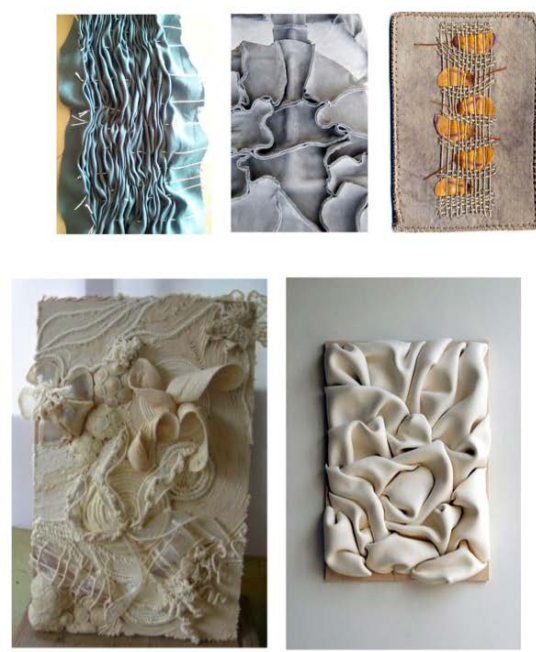
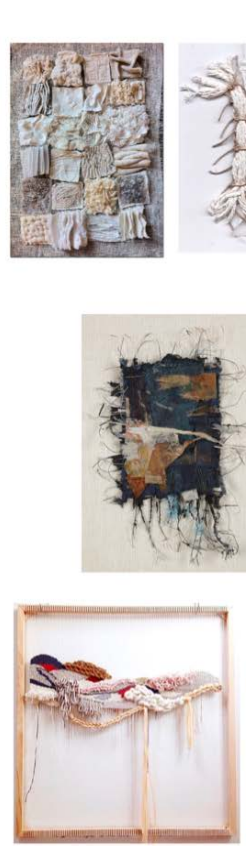
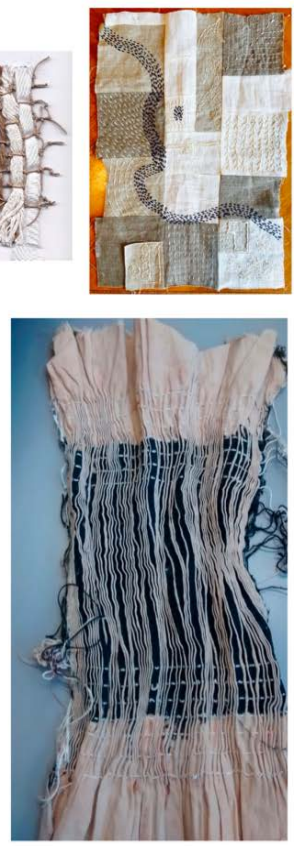

Figure 4. Pictures and samples of some fabrics collected. 


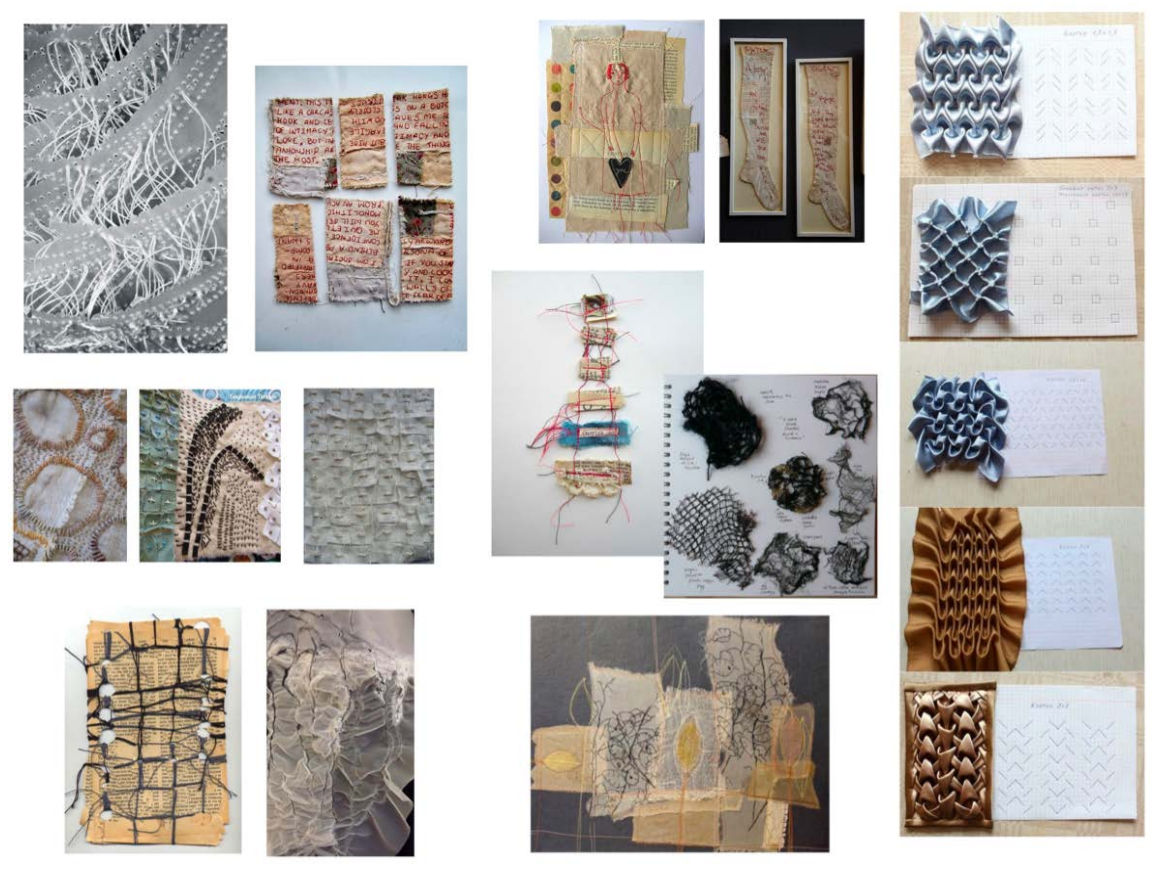

Figure 5. Pictures and samples of some fabrics.

The secondary design of clothing focused on the selection and composition of fabric colors, fabrics types, and patterns, which may influence the final product's texture greatly. The methods can be divided into the following categories:

1) Dyeing. This method can be hand-painted or sprayed with splash ink to offer a comprehensive color effect.

2) Printing. Partial screen printing of screen-making is a more commonlyused method, where the printing paste flows into the fabric pattern and is transferred onto the fabric later.

3) Multi-layer design. The weaving form of the fabric can be artificially changed by gap shrinking and form a three-dimensional effect on the original fabric surface.

4) Increase the design. The fabrics of different materials can form different contrast effects by adopting the method of stitching and hotpressing.

5) Subtractive design. By using the method of sand washing, more shapes and surface characteristics can be added to the original surface of the fabric (Yueming, 2017).

Another critical role of clothing is color. It offers the customers a direct impact on vision. As a result, color transformation is also a critical role in the recreation of clothing. In color transformation, painting skills like tie-dyeing, hand-painting, stitching, and even digital painting are used nowadays, combining all painting creativities and modern technologies. The invisible value of the clothing is increased at the same time.

\subsubsection{Upcycled Clothing}

Upcycled clothing takes old, worn out, or damaged materials and transforms 
them into new pieces (James, 2020). It is also referred to as repurposed, reused, or recycled clothing. Upcycled garments are becoming increasingly popular in the modern fashion industry.

The critical difference between upcycled and recycled clothing is that brands use whole pieces of existing garments to create new clothing. While in the perspective of recycled clothing, materials must be broken down before they can be reused.

There are many environmental benefits of upcycled pieces. Upcycled clothing uses significantly fewer raw materials, which helps to reduce the harmful impacts of fashion production on the natural environment.

Less water usage, fewer chemicals and carbon emissions, fewer contributions to the landfill are benefits of upcycled clothing. They can be raw and straightforward, rather than the pieces commonly seen in fashion stores these days.

\subsubsection{Top Recycled and Upcycled Businesses That Practice the Reconstruction}

(fabrics

https://compareethics.com/9-recycled-and-upcycled-clothing-brands-you-shoul dnt-pass-in-2018/)

1) Beyond Retro

Beyond Retro is a vintage retailer. Its buyers search through thousands of vintage pieces but only select and pay for one out of a thousand. The brand launched an upcycled Label made only from secondhand fabrics for the rest of the unselected pieces.

After sorting the rest pieces into vast piles of fabrics, the company redesigns the fabrics into the latest trends, upcycling them for the new season. The redesigned clothes are all at affordable prices, which can attract more consumers at the same time.

2) Patagonia

Patagonia is one of the founding pioneers of ethical fashion. This outdoor wear brand has started using recycled plastic bottles to make their garments since 1993.

Patagonia uses recycled plastic to create fleeces, shorts, and jackets. It also operates its recycling scheme-if you own a piece of Patagonia clothing that can't be repaired, you can return it to one of their shops to be recycled and reused. This style of recycled clothing saves tons of textiles and prolongs the materials' lifespan.

3) Fanfare

Fanfare is a British fashion brand that follows the guidance of sustainability in the industry. Compared to the popular fast high street fashion, the brand launches its collection once a year. Besides this, Fanfare also redesigns vintage pieces into new ones, mainly denim and outerwear. The company upcycles them into spectacular designs alongside product wastes.

4) /id/ 
The /id/ brand was created into a sustainable fashion brand that enables women to express themselves through the pieces that choose from the brand.

Each piece of clothes from this brand is made of the highest quality "deadstock" fabrics (James, 2020). Deadstock fabrics are "surplus fabrics that were not sold by the textile mills and left in storage" sourced from Europe. /id/ is focused on handcrafting and handmade materials (presented in Figure 6).

\section{5) RubyMoon}

RubyMoon sells activewear pieces. Its gym and sustainable swimwear are created from used fishing nets and abandoned plastic bottles collected from the ocean. By turning polluting waste into the garments from the brand, the company has reduced its carbon footprint by $42 \%$.

The brand is dedicated to a circular economy. It practices swimwear and other stretches, elastic fabrics to re-use in their upcycled clothing line. RubyMoon also has its take-back scheme to promote its circular fashion conception.

6) Re/Done (see Figure 7)

$\mathrm{Re} /$ Done is a vintage brand that focuses mainly on denim. It turns vintage denim into new jeans. Every pair is made from water-conserving methods rather than commonly used chemicals.

The brand also keeps the original stitching in place as much as possible, preserving history and stories stored in every pair of jeans throughout the years. The amount is limited, so every piece of clothing is handpicked and hand-cut.

7) Ecoalf

Ecoalf started in 2009 and has been focused on recycled fabrics since then. Ecoalf has started multiple projects aiming to clean up the Oceans from plastic. They actively collect junk from the ocean and recycle them by turning them into new, fashionable pieces.

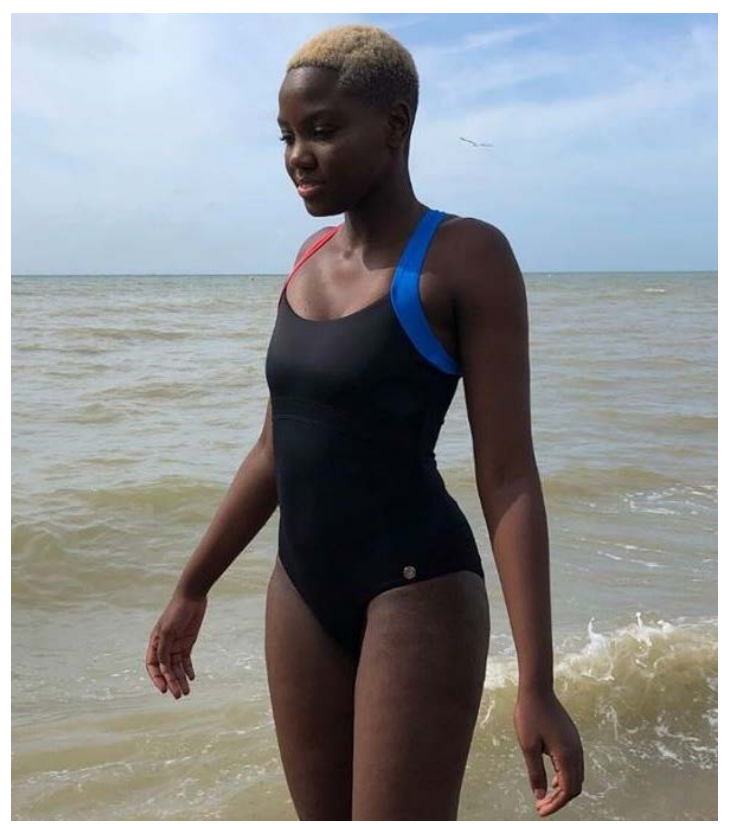

Figure 6. A model wearing the brand /id/. 


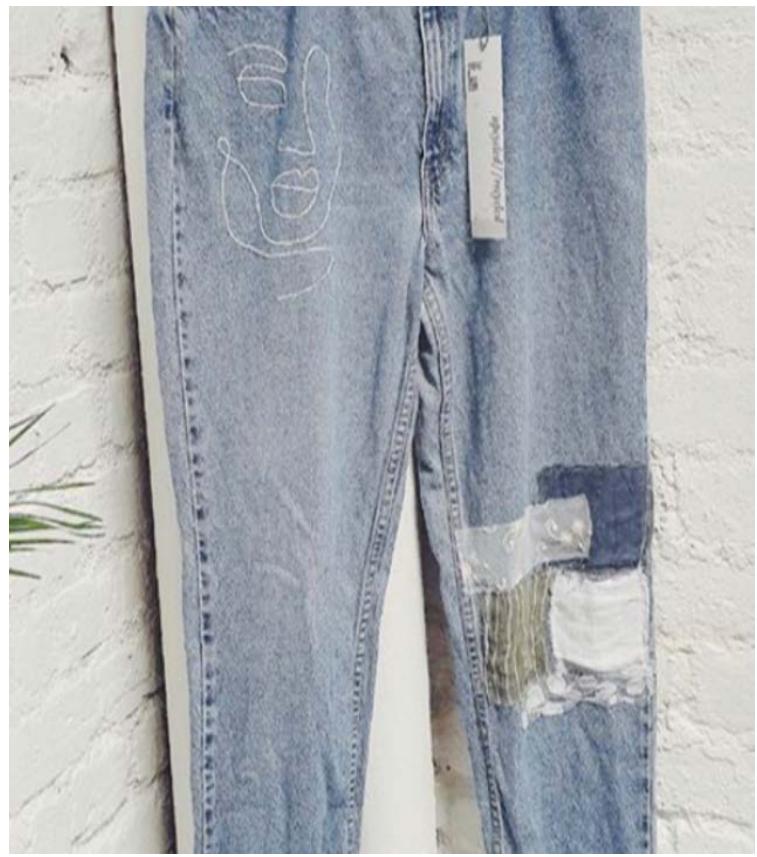

Figure 7. A jean from brand Re/Done.

\subsubsection{Brands That Upcycle}

There are also plenty of other brands doing a great job reusing materials in their clothing production and fabrication process.

1) Antiform

Antiform is an English brand based in Bristol. The brand mixes reclaimed materials with traditional handcrafts. It forms a full local expertise production line, from the materials to the factory.

2) Urban Renewal

Urban Outfitters doesn't have a good record for its production practices like some other high street brands. But they have introduced their very own upcycled range recently. The brand looks for surplus materials or deadstock products from former seasons.

Rather than ending up in landfills, the team at Urban Renewal modifies them into new fashionable pieces.

3) ASOS Reclaimed Vintage

ASOS is also joining the upcycled clothing team. ASOS has been making moves in making their clothes more ethical by launching their ASOS Eco Edit range and their ASOS Reclaimed line.

\subsubsection{Information and Exhibition of Clothing Reconstruction}

Academic research: reconstruction is making new clothes, even couture ones from worn ones (Mary, 2016). Nowadays, 60 percent more clothes are consumed than a decade ago, which caused the proportional increase of waste at the same time. Many clothes are still in excellent condition when being deserted into the landfills. Around 140 million pounds worth of used clothes is abandoned in the United Kingdom alone every year. The human labor resources behind the production of 
these fabrics, materials, and pieces cannot be neglected. When the clothes are thrown into the landfill, the efforts are also wasted to a degree. By reconstructing garments, not only the fabrics' lifecycle can be prolonged, all the demands of artificial and natural resources will be decreased at the same time (WRAP, 2012).

Reconstruction has often been mistaken as an exclusive design pathway, considering its difficulty and complexity; this depends on the type of reconstructed garments. The time and efforts required vary broadly (WRAP, 2012). The following part will be about some brands famous for clothing reconstruction.

Example 1: Christopher RAEBURN (https://www.raeburndesign.co.uk)

Christopher Raeburn is a brand that fuses high fashion with sustainability. Its founder has always been challenging the industry for its eco-friendly targets. $\mathrm{He}$ only picks unwanted, redundant materials for new series of product designs.

RAEBURN items have been created, taking existing surplus materials, products and artifacts and reworking them into entirely new products (see Figure 8).

Example 2: Needles (see Figure 9) (https://www.needles.jp/)

This label explores the possibility of mixing American and Japanese shapes and fabrics. The brand has over 30 years of history.

Example 3: Bethany Williams London (see Figure 10)

(https://www.fashionrevolution.org/usa-blog/7-fashion-brands-that-are-desig ning-out-waste/)

This brand developed hand-woven textiles from recycled packaging materials. The clothes were handmade by people from a rehabilitation school in Italy. The founder wanted to offer a sense of participation and community to those people as well.

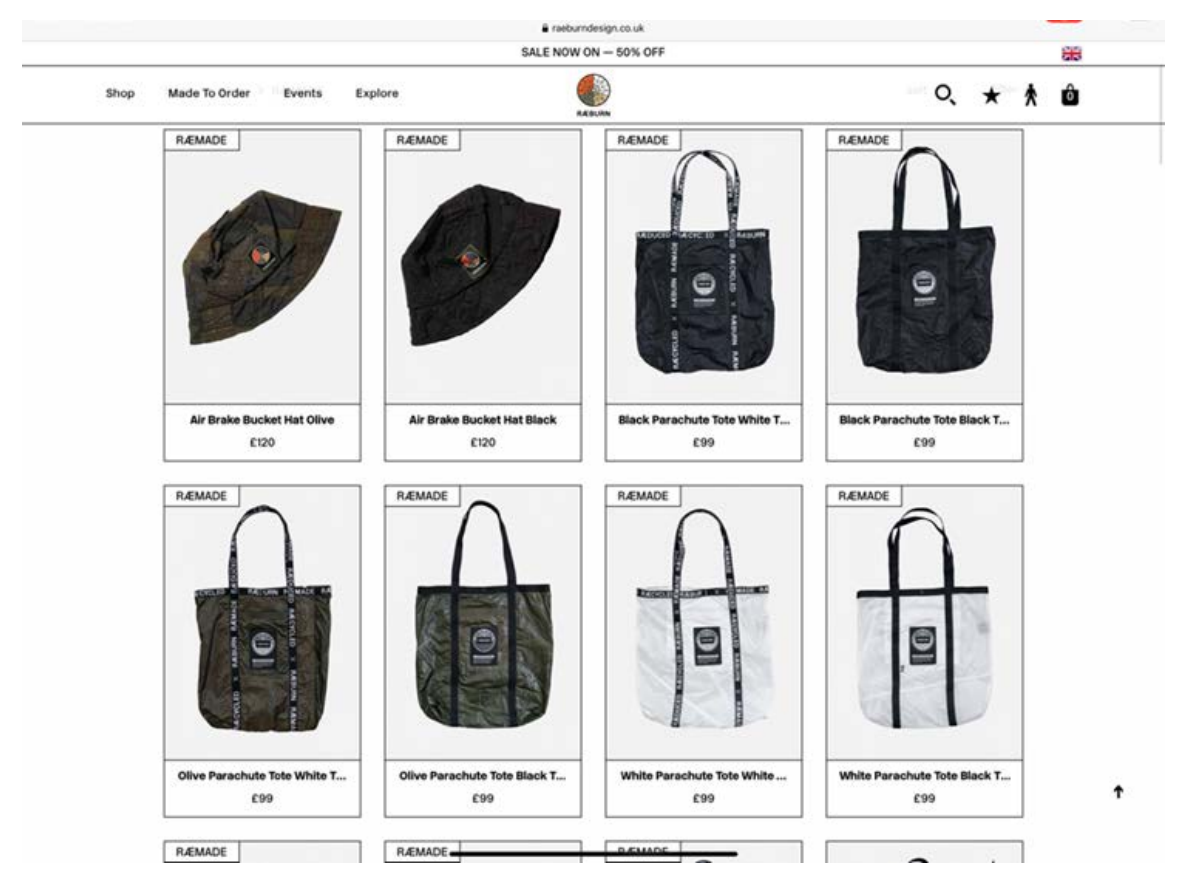

Figure 8. Products from Christopher Raeburn. 


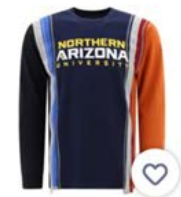

Needles

7 Cuts Long-sleeve T-
shirt - Blue

$\$ 23874$ (40\% off)

C Cettire

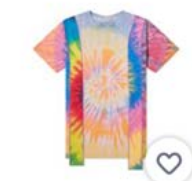

Needles

5 Cuts Tee - Multicolour

(35\% off)

Q END.

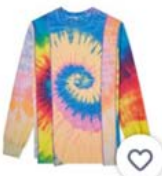

Needles

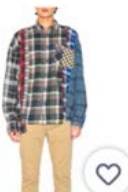

Needles

Wide 7 Cut Flannel Multicolour

- 2281

e Forward

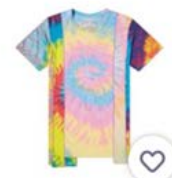

Needles

5 Cuts Tee - Multicolour

- 195 (35\% off)

Q END

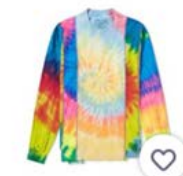

Needles

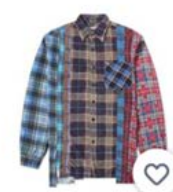

Needles

7 Cuts Flannel Shirt

Blue

- 2225

P ENDD

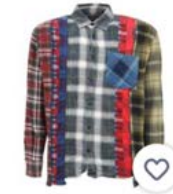

Needles

7 Cuts Cotton Flanne Shirt - White/blue G256

e LUISA VIAROMA

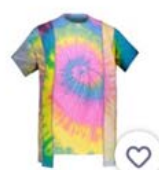

Needles

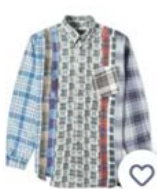

Needles

Rebuild 7 Cut Shirt - Blue

W145 (35\% off)

C END.

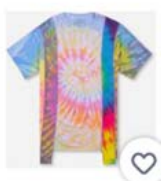

Needles

Tie Dye Cuts T-shirt -

$\$ 775$ £90 (45\% off)

Q The Hip Store

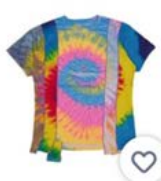

Needles

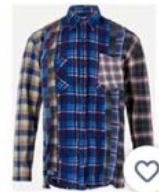

Needles

7 Cut Check Shirt - Blue

\& 230

c) Liberty London

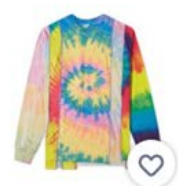

Needles

Long Sleeve 5 Cuts Tee Multicolour

- 2145 (35\% off)

C) END.

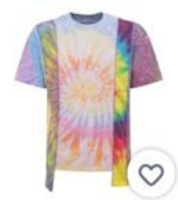

Needles

Figure 9. Products from needles.

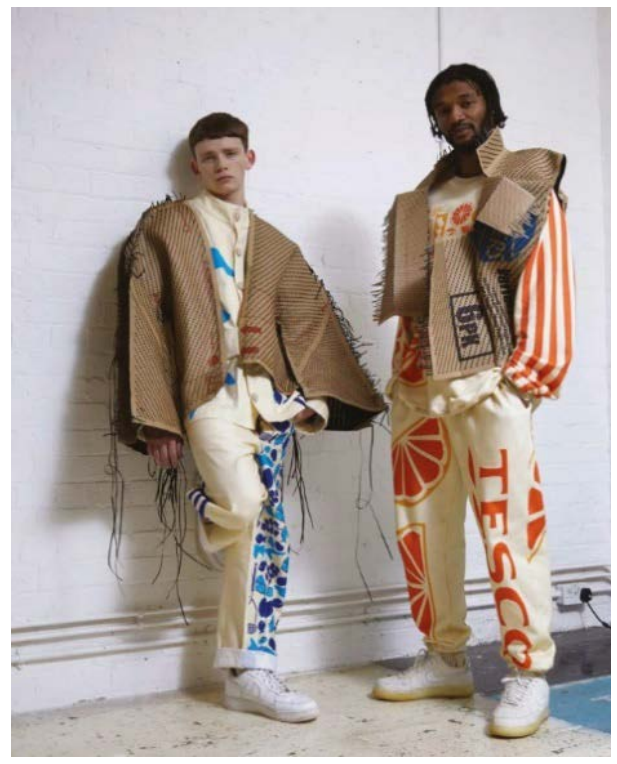

Figure 10. Products from Bethany Williams London.

Example 4: Ecoalf

(https://www.fashionrevolution.org/usa-blog/7-fashion-brands-that-are-desig ning-out-waste/)

The Spanish brand Ecoalf was founded on the principles of recycling. The founders intend to create a genuine, sustainable fashion brand that applies $100 \%$ 
recycled materials (shown in Figure 11). From deserted fishing nets to plastic bottles thrown randomly on the beaches and streets, the company uses them to reproduce the best quality of outerwear and accessories (cited in Fashion Revolution).

Example 5: Doodlageofficial

(https://www.fashionrevolution.org/usa-blog/7-fashion-brands-that-are-desig ning-out-waste/)

Doodlage is an Indian brand who always follows the rules of sustainability and innovation (shown in Figure 12). They only use eco-friendly fabrics including organic cotton, corn fabric and banana fabric. They think it is a good practice to offer wastes a second life rather than going into landfills (Sass, 2017).

Example 6: Recode (see Figure 13)

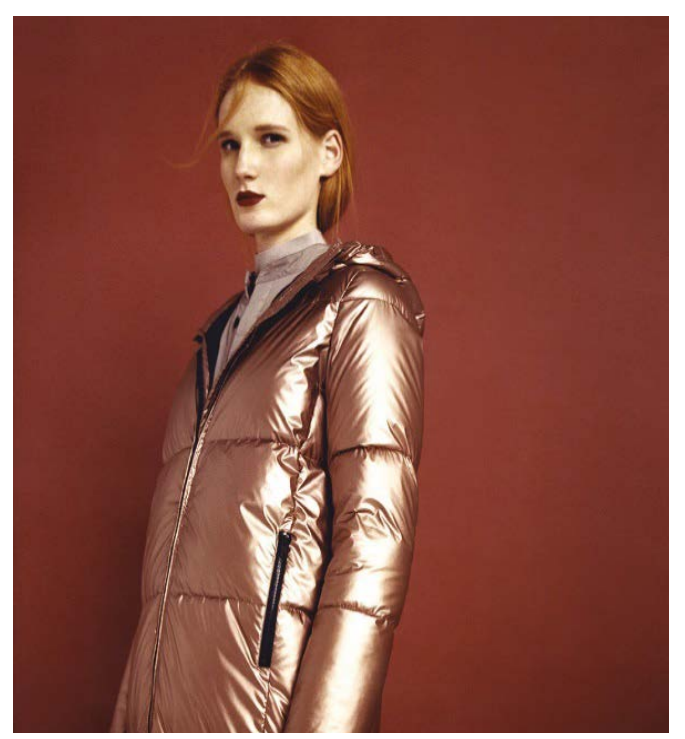

Figure 11. Products from Ecoalf.

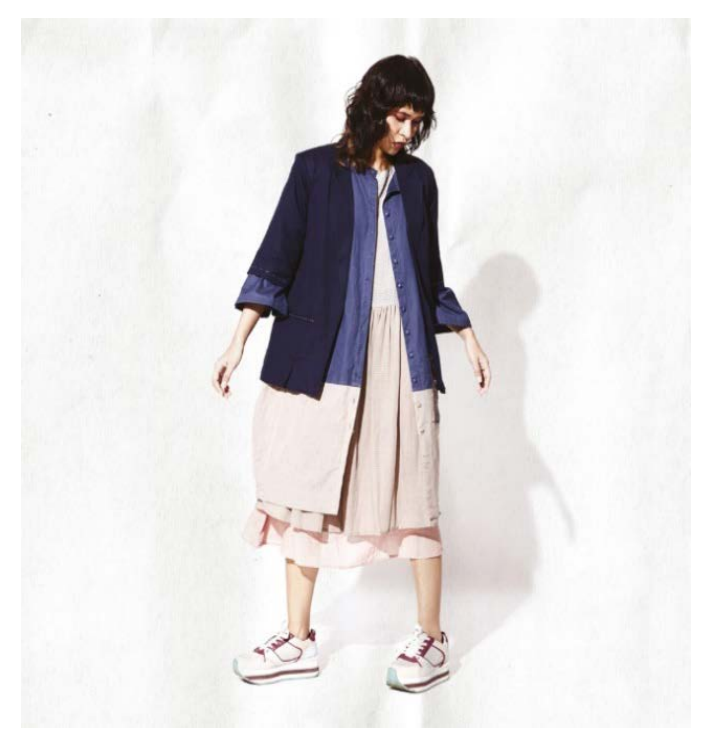

Figure 12. Products from Doodlage official. 


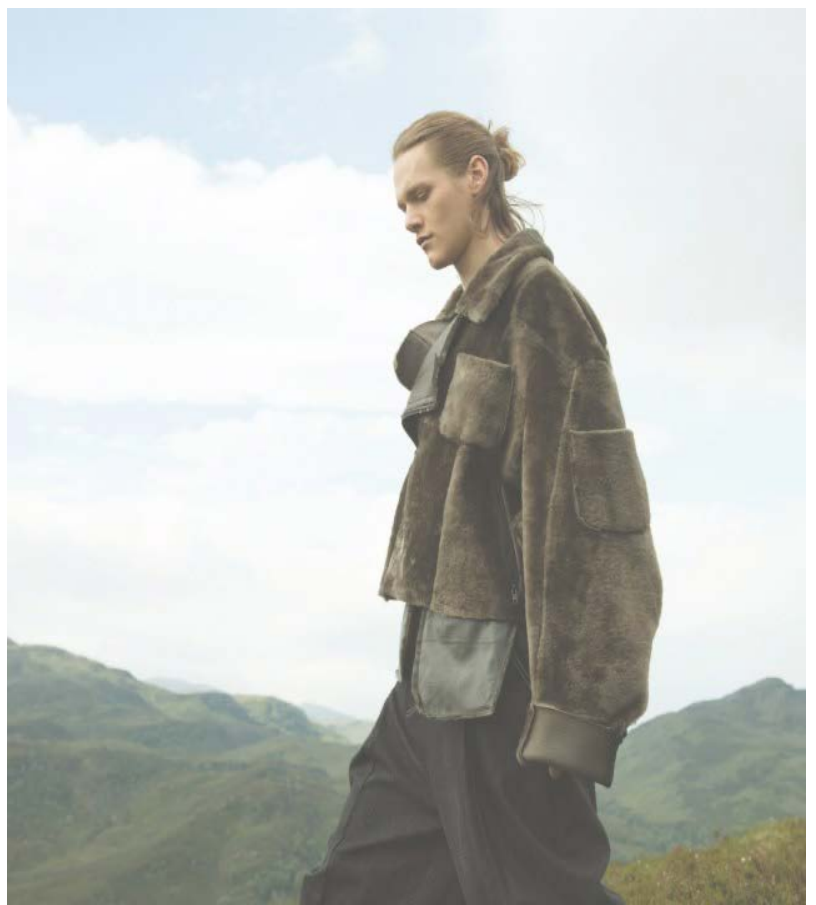

Figure 13. Products from recode.

(https://www.fashionrevolution.org/usa-blog/7-fashion-brands-that-are-desig ning-out-waste/)

Recode is a South Korean brand famous for its upcycling concept. The brand works with the charity shops ("goodwill shop" in South Korea) to select, disassemble and redesign abandoned materials (Sass, 2017).

\subsubsection{Observation of How Senior Designers Combine Used Items with Clothing}

1) Academic research

First, it is essential to determine what kind of waste can be used to make clothes. Besides the fundamental clothing requirements, designers and manufacturers are three ground rules for comfort, hygiene, and safety. From this point of view, garbage such as metal, plastic

(https://www.trvst.world/sustainable-living/fashion/turning-plastic-waste-into-c lothes/), ceramics, and wood is not suitable for making clothes. The most commonly used garbage materials, including old clothes, paper, etc., can be worn as clothes for various purposes after processing (Sogou, 2019).

As previously discussed, the most direct and easiest way to use waste to make clothes is to transform old clothes into new clothes. It directly uses the original materials and has fewer processing steps while still a voice for different personalities. The traditional transformation is transforming adult clothes into children's clothes or transforming large clothes into small clothes (Sogou, 2019).

In Europe, there is a process that discomposes waste paper fibers and "redraws" them into making clothes, which is nearly the same way as papermaking. This condition has been practiced in some Japanese clothing colleges; students 
use local newspapers, old magazines, and other waste paper to make environmentally friendly fashions to display at environmental protection exhibitions. They set good examples, but the comfort of these clothes is doubtful (Sogou, 2019).

Plastic bags can also be used as clothes. The shopping bags we use to carry goods from shops are the raw material for clothing. The most direct way is to pile up several layers of plastic film from the spreading out shopping bags, glue them into a thicker film with an electric iron, and then cut them into homewares like the aprons. The new output is waterproof and clean (Sogou, 2019).

It is critical to ensure that the waste products are disinfected and cleaned before clothes making. I need to pay attention that clothes made of excessive waste materials may not be suitable for children, which is due to the weaker immunity of children, and they are more likely to be infected by remained bacteria from unproperly processed waste. As a result, adult clothes have a higher chance of applying waste products as material (Sogou, 2019).

Clothes made from waste should also be considered its practicability. T-shirts, pants, hats, long skirts are scarves are more likely to be made from waste products (Sogou, 2019) (see Figure 14).

\section{2) Practical research}

In this part, some research on clothing brands will be presented with pictures attached under a specific brand.

Example 1: Gary Harvey (see Figure 15)

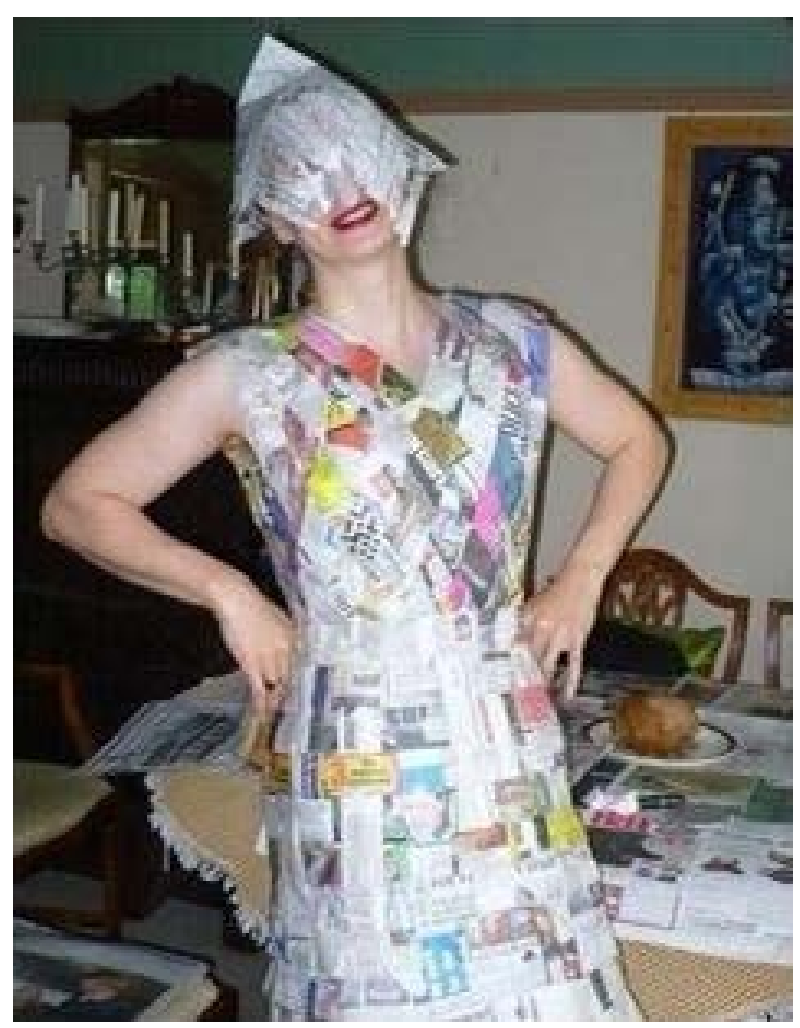

Figure 14. Dress designed using waste products. 
The dress displayed on the runway was made out of 30 copies of the Financial Times. It is a tip and an alert to tell the world how recycling fashion can contribute to the economy from another perspective.

Example 2: Joann Berman (see Figure 16)

This brand uses old denim, shirts, military uniforms, logo T-shirts, laundry bags, and even cardboards to turn them into colorful gowns and dresses. It is a bold, innovative practice of turning waste products into ready-to-wear.

Example 3: Liora Lassalle (see Figure 17)

Liora Lassalle reused the abandoned workmen's jackets and turned them into totally different clothes.

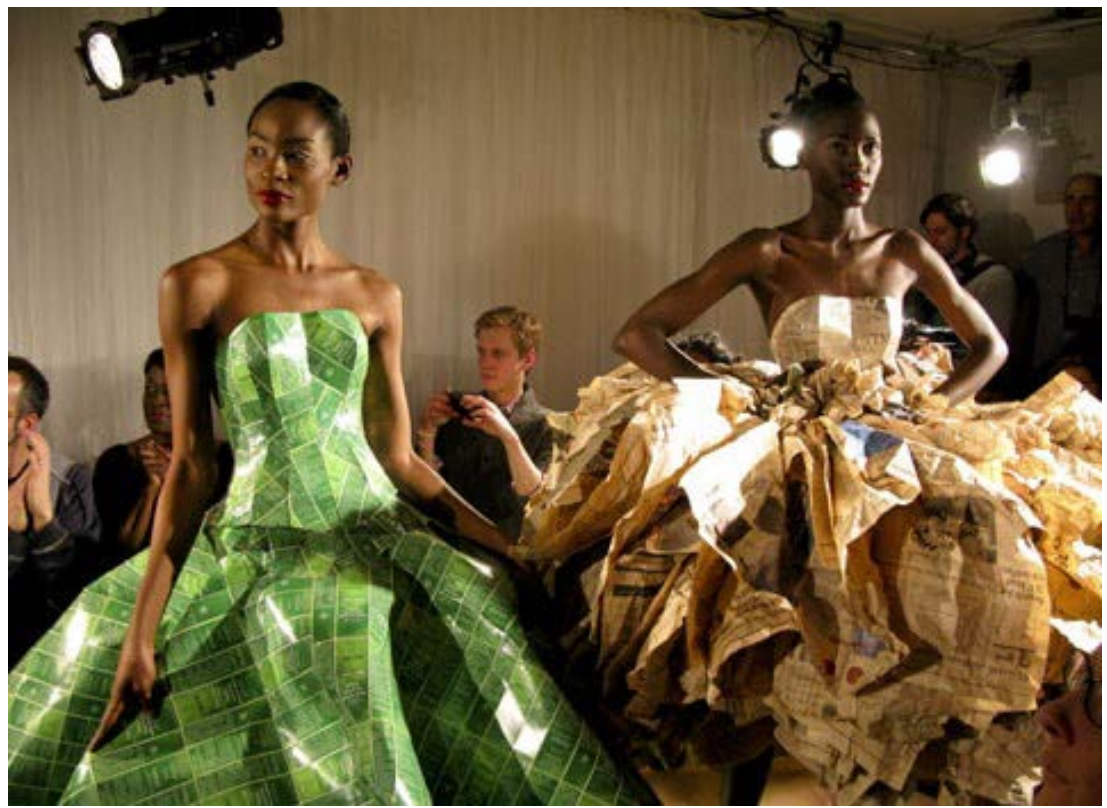

Figure 15. Dresses from Gary Harvey.
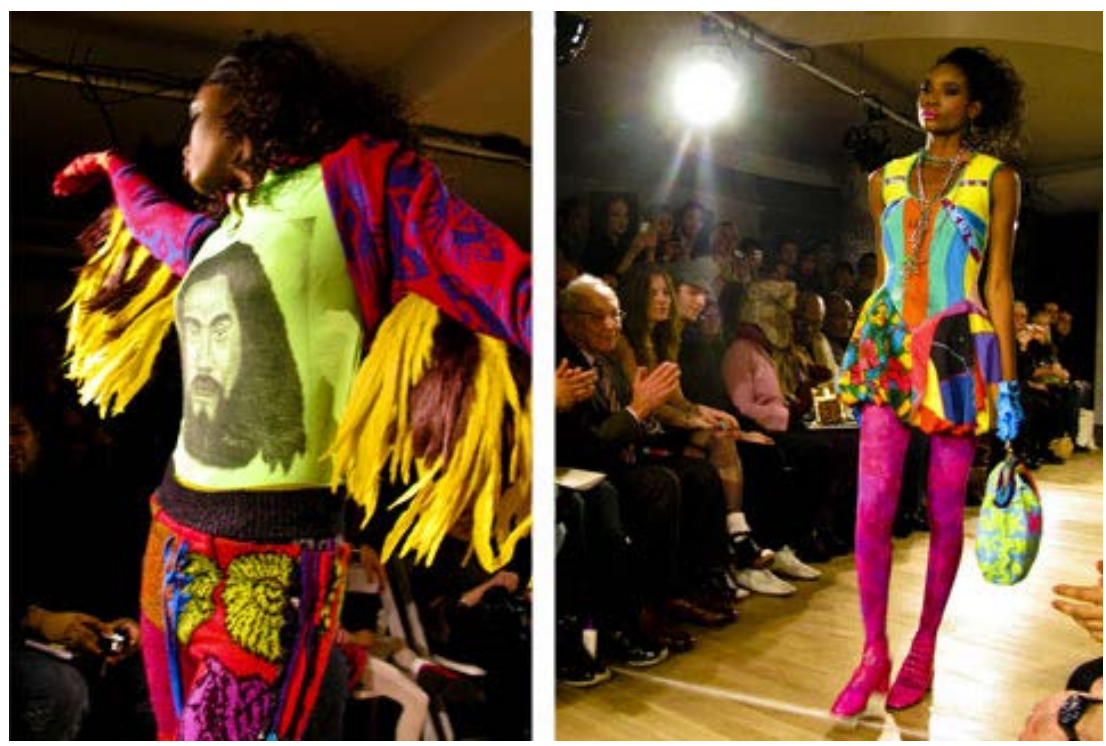

Figure 16. Dresses from Joann Berman. 


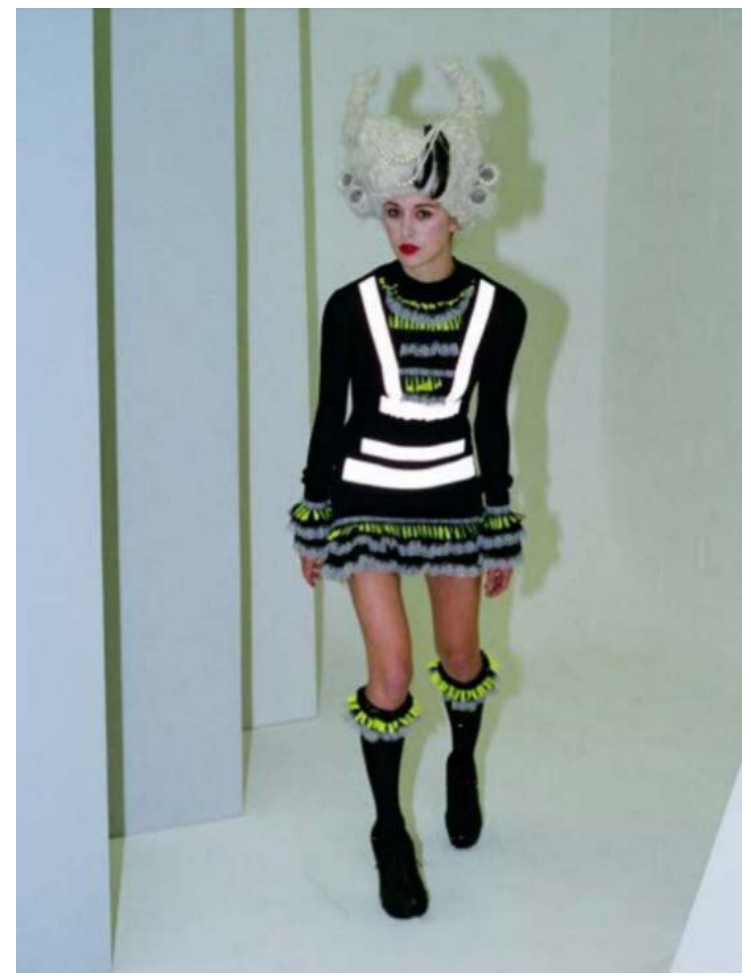

Figure 17. Dresses from Liora Lassalle.

\subsection{Methodology}

\subsubsection{Three Key Points}

- Create the fabric from waste materials.

- Reuse the recreated fabric.

- Combine different fabrics into one new piece of fabric.

To reuse the materials, I collected coasters made of wool felt balls (presented in Figure 18) and dance veils (presented in Figure 19) that kids no longer wear. I cut the wool felt ball on the coaster and separated the gauze skirt. Then I combined the two parts and stacked them up layer by layer with different layouts, forms, and match patterns.

\subsubsection{Making Methods}

Regarding the connecting methods, it varies with the type of fabric form I worked on. In this project, the primary method is stitching (referring to Figure 20).

\section{Research \& Design}

\subsection{Summarize}

Through the research and study of the business model, my research mainly discusses the recreation of waste and fabrics; how to reuse them and recreate these materials into sustainable pieces of clothing.

I summarized a series of manufacturing methodologies to reuse and redesign a physical piece. 


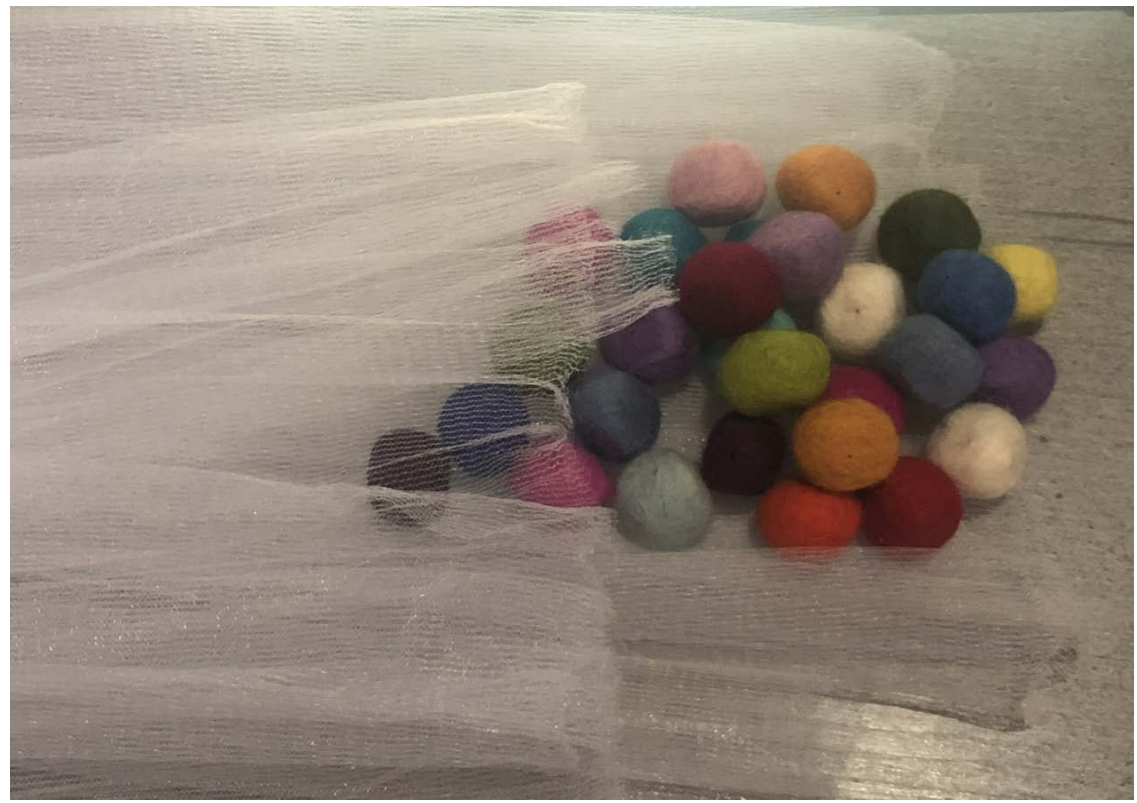

Figure 18. Wool felt balls.

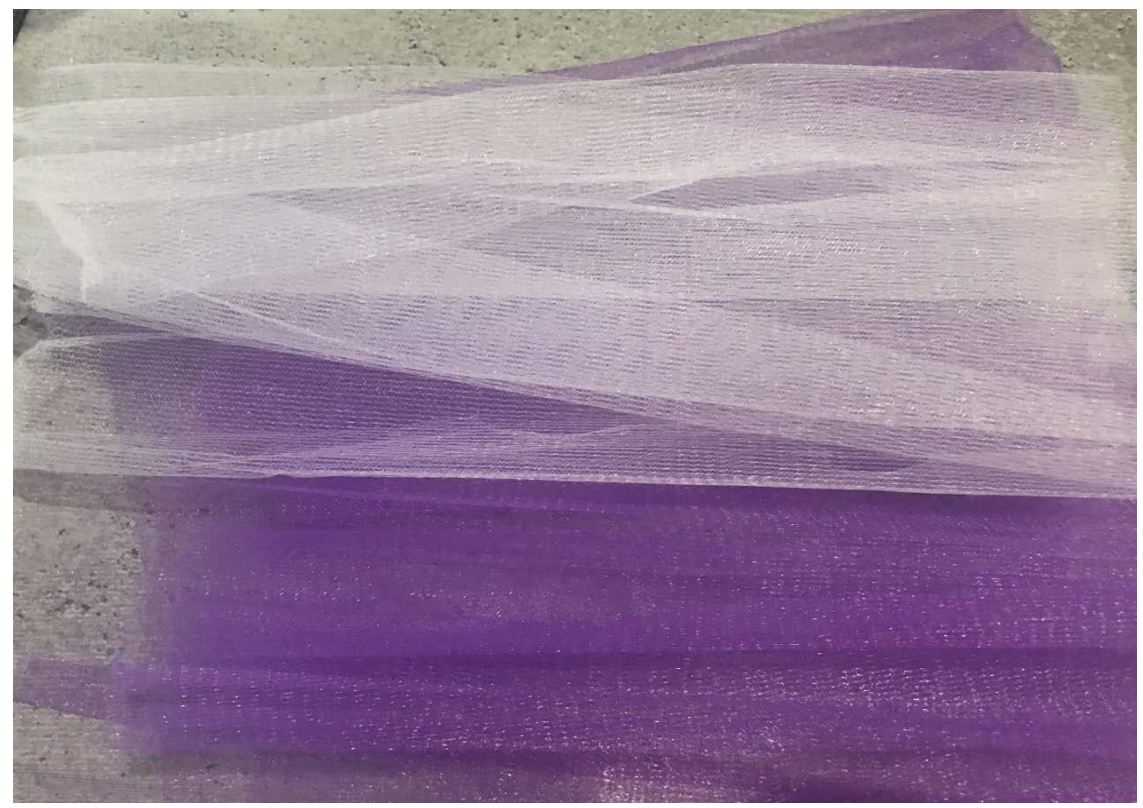

Figure 19. Dance veil.

1) The remaining fabrics in the production process are sorted and recycled while the company redesigns the fabrics.

2) Recycle clothes sold by the brand itself.

3) The remaining waste of each piece of clothing becomes the embroidery and embellishment of the garment.

4) Customers who send back second-hand products from the company will get a discount on their next purchase.

5) Zero waste cutting method.

6) Collect garbage from the ocean for recycling. 

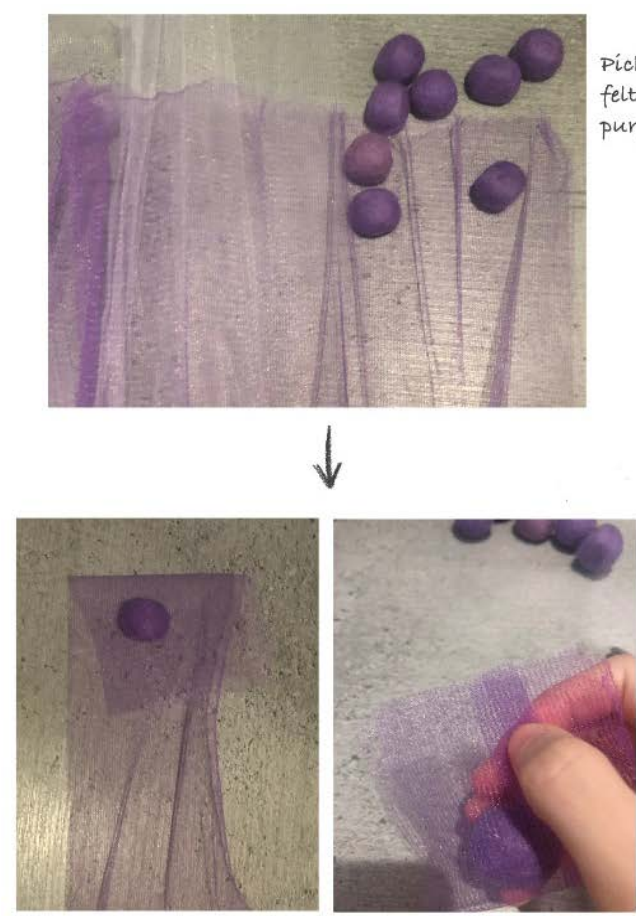

cut a small piece of ganze, and then stitch a purple wool felt ball into the gauze. In this way, a new small piece of recreate fabric is formed.

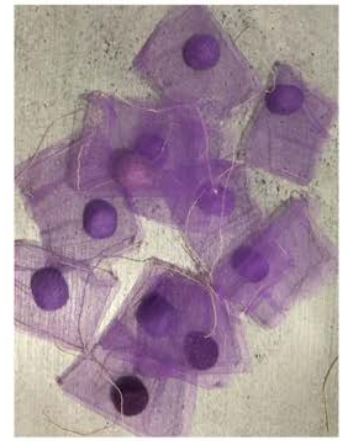

Several new recreate fabrics are stitched together.

In addition to making these small recreate fabrics, which are stitched wool felt balls and purple gauze, I also need to make a larger piece of new fabric that can be combined with these small fabrics.
Pick the purple ball from the wool felt ball and match it with the purple gauze.
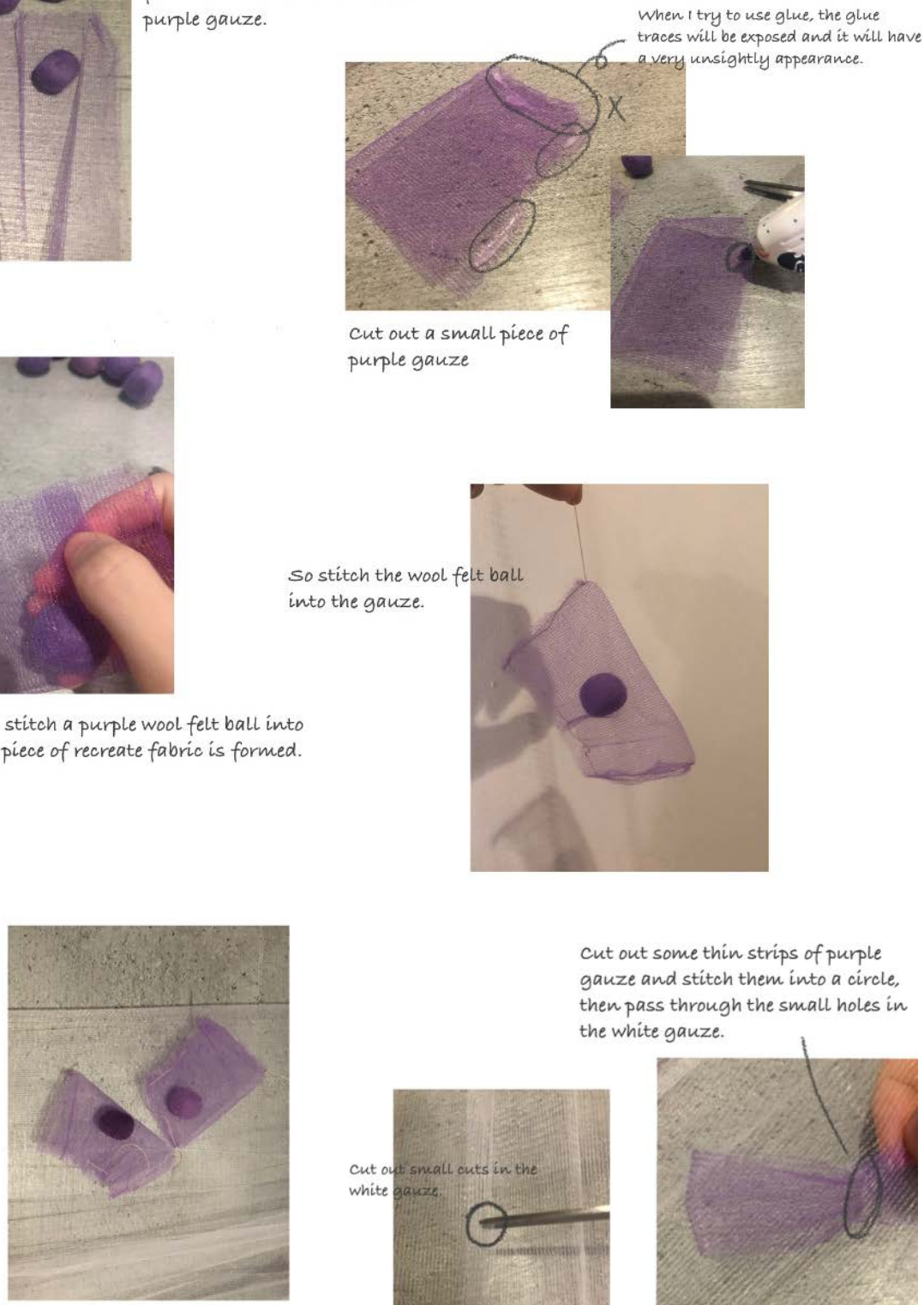

Put them on the white gauze of the veil.

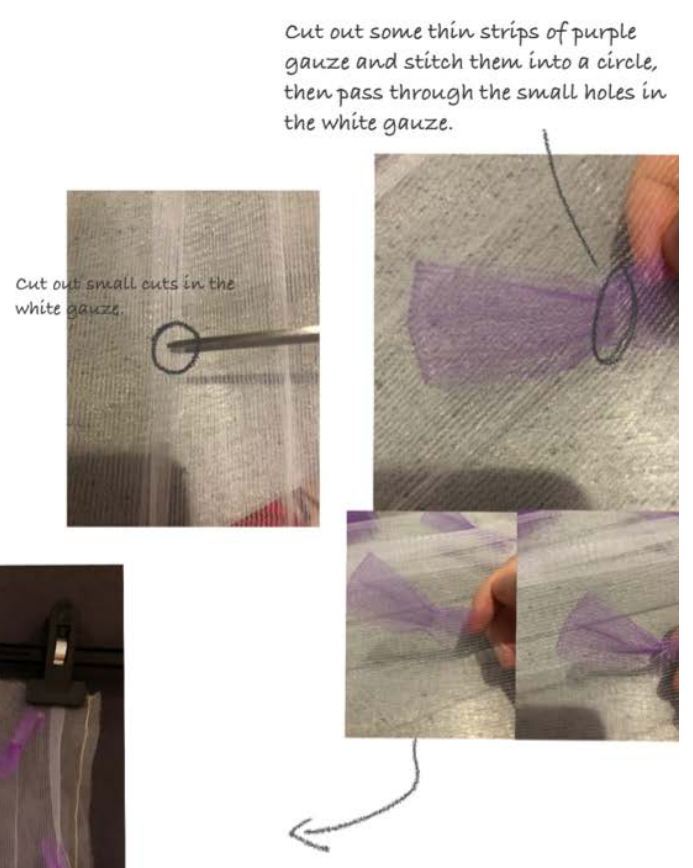

Finally form a new recreate fabric

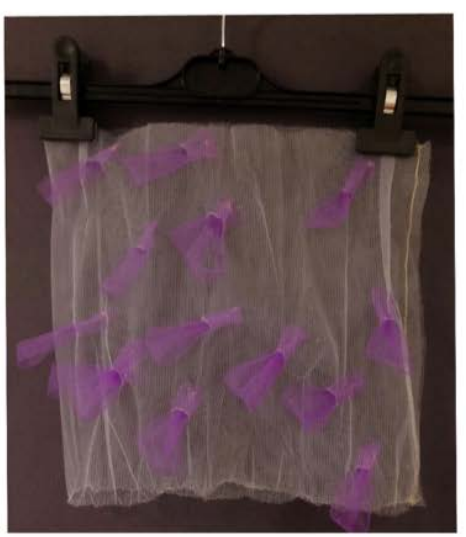




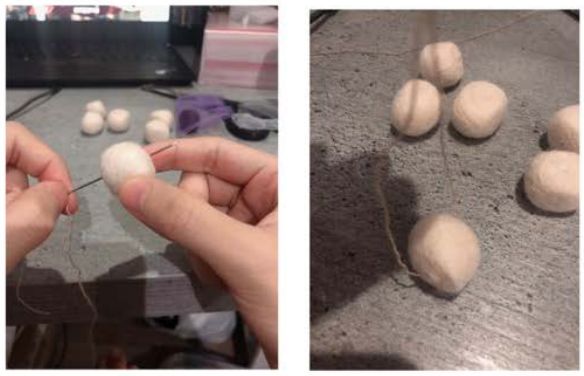

Pick out all the white balls of the sweater coaster, and thread the balls through them so that they can be hung on other things.

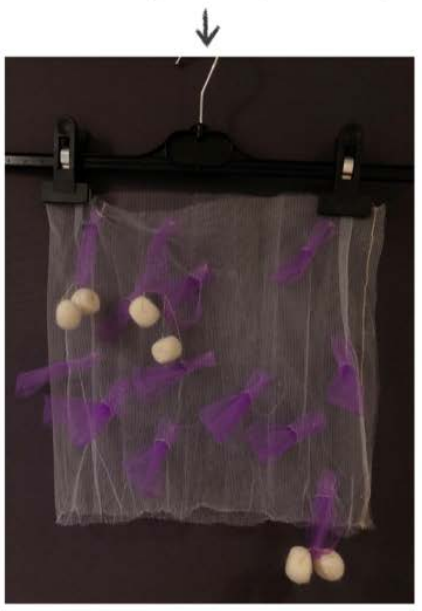

Hang them in the purple circles on the large recreate fabric.
Two white wool felt balls to ensure that they will not

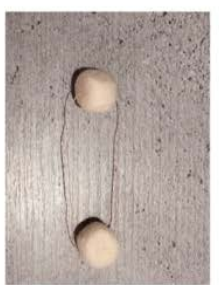
together with purple wool felt balls and purple gauze can also be hung on white wool felt balls.
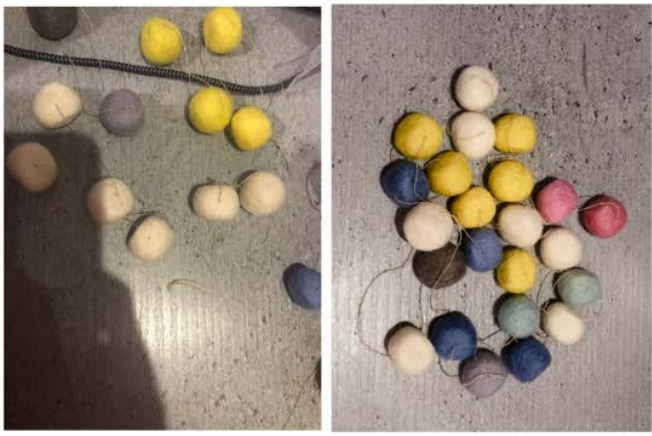

The small recreate fabric stitched

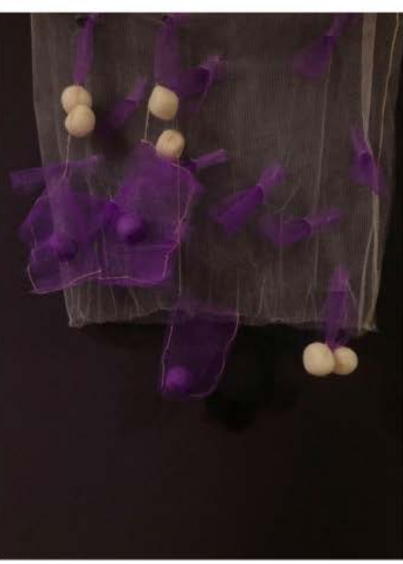

Thread other colored wool felt balls (two to three).
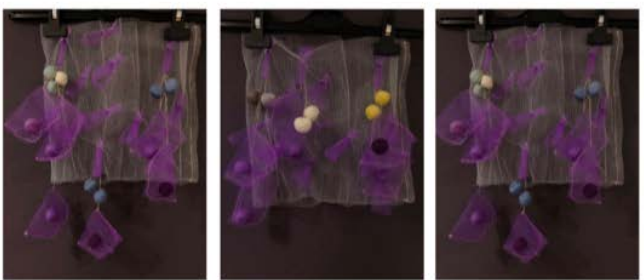

The purple recreate fabric is combined with the large recreate fabric through different layouts, different forms, and different matches.
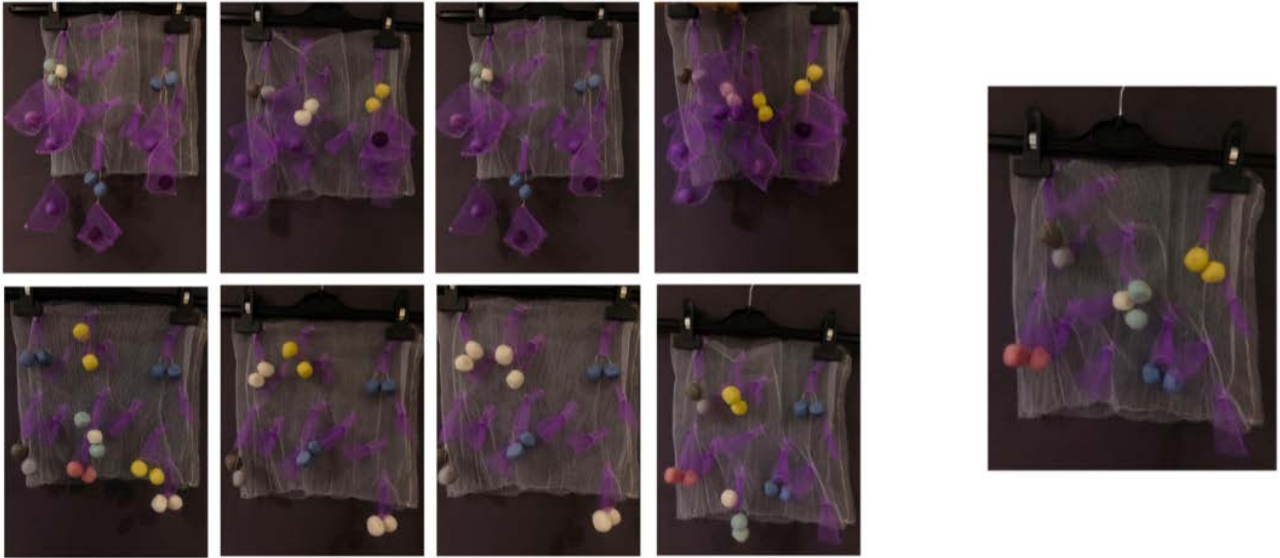

Figure 20. Stitching process. 


\subsection{Primary Research}

\subsubsection{Simple PDS}

Before the primary research, it is necessary to create a simple PDS, which clearly states what will be achieved with a purpose.

- Reflection

Through the reflections on the previous practice, I successfully rendered the initial fabric reconstruction process (see Figure 21). However, due to its instability, it is not easy to combine with existing clothing, nor is it easy to display. Therefore, the practicality of recreating the fabric requires more in-depth study.

In general, I set several guidelines of manufacturing methods to demonstrate how to make different reconstruction design and how to reuse the fabrics.

\subsubsection{Guidelines}

\section{For Reconstructing Garments}

- Use a pattern or a part of the pattern, for instance, the bodice of a dress pattern. The original garment needs to have sections of fabric that are large enough for the new pattern pieces.

- Combine more than one garment.

\section{STEPS TO EFFECTIVE}

\section{A project development specification}

\begin{tabular}{|c|c|}
\hline \multirow{3}{*}{$\begin{array}{l}\text { Do some researches and } \\
\text { learn the practice of } \\
\text { fabric reconstruction, } \\
\text { such as methods, crafts, } \\
\text { and techniques. }\end{array}$} & \multirow[b]{2}{*}{ Collect fabrics } \\
\hline & \\
\hline & \multirow{2}{*}{$\begin{array}{l}\text { Collect fabrics of different } \\
\text { styles, colors, and materials, } \\
\text { and observe their structure } \\
\text { and texture. }\end{array}$} \\
\hline \multirow{3}{*}{$\begin{array}{l}\text { Combine the collected } \\
\text { fabrics in different ways } \\
\text { to make a new } \\
\text { finished product. }\end{array}$} & \\
\hline & Collect wastes \\
\hline & \multirow{3}{*}{$\begin{array}{l}\text { Collect soft objects } \\
\text { discarded in daily life, } \\
\text { such as mesh bags, } \\
\text { woolen yarn, wool felt } \\
\text { coasters, etc. }\end{array}$} \\
\hline \multirow{4}{*}{$\begin{array}{l}\text { Use methods such as } \\
\text { weaving, sewing, and } \\
\text { pasting to combine } \\
\text { them into new } \\
\text { recycled fabrics. }\end{array}$} & \\
\hline & \\
\hline & Design Sketches \\
\hline & \multirow{3}{*}{$\begin{array}{l}\text { Combine recycled } \\
\text { fabrics with clothing, } \\
\text { draw sketches, and } \\
\text { determine their location } \\
\text { and aesthetics. }\end{array}$} \\
\hline $\begin{array}{l}\text { Combination } \\
\text { with clothing }\end{array}$ & \\
\hline $\begin{array}{l}\text { Combine them on the } \\
\text { garment according to } \\
\text { the position of the } \\
\text { design sketch to } \\
\text { become new garments. }\end{array}$ & \\
\hline
\end{tabular}

Figure 21. Stitching process. 
- Add fabric which never been used in a garment before; for example: make a purse out of a leather skirt but use fabric from your stash to line it.

- Look for quality fabrics when sourcing garments to transform them.

- Look for large, uncut panels of fabric on garments to use.

- For designing a reconstructed garment.

- Study the garment's original design and fabric to find potential innovation.

- Look for interesting features that can be remained. The fabric type and the shape will influence the design of the new garment.

- Consider any size/fit changes required to the original garment, for instance, decreasing or adding in more width or length. Additional fabric can also be incorporated into the new design.

- Look over the fabric of the original garment and evaluate if the stains are in place, if the threadbare can be worn anywhere else, or if there are moth holes. They all be repaired or covered with a design detail like ruffles or pockets.

- A garment can be changed with a simple adjustment such as shortening or lengthening, changing the buttons, removing or adding details like pockets, collars, and ruffles.

How to Reconstruct a Garment

- Clean the garment if it is bought second-hand or it's ancient. Sometimes a piece of clothes cannot be washed through the water directly.

- Take the entire original garment apart to use the fabric differently or a flat pattern.

- Take off only pieces that will not be part of the new garment like sleeves, front plackets, collars, or patch pockets.

- Start building the new garment and update the design through production. Invite a volunteer as a model.

- Use the same construction techniques as much as possible. Some seams may need hand-stitched, topstitched, or machine stitched.

- An interface can be added if needed in new garment construction.

- Quilting will support weak areas in the original garment or any textile if needed.

- Facings or bindings can be made from other fabrics or garments if there is not enough fabric from the original garment.

- Facings may be needed to a seam. The aim is to put in a zipper or a placket for buttons or turn under to seam.

- Ruffles and more minor details can hide stains and patched areas.

- In addition, the practical work I need to do is to recreate fabrics and reconstruct fabrics that can be truly integrated with clothing and displayed on the clothing.

\subsubsection{Secondary Research}

\section{Design}

The connection between secondary and primary research is to pick the proper methodology and justify the research methods. 


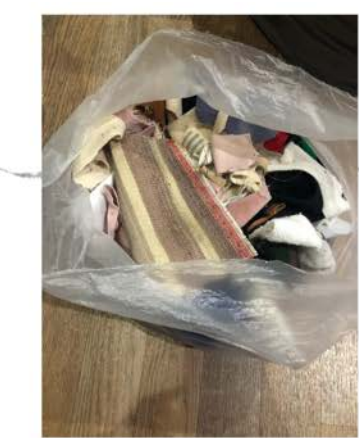

Some waste fabrios collected from the clothing reoyoling bin
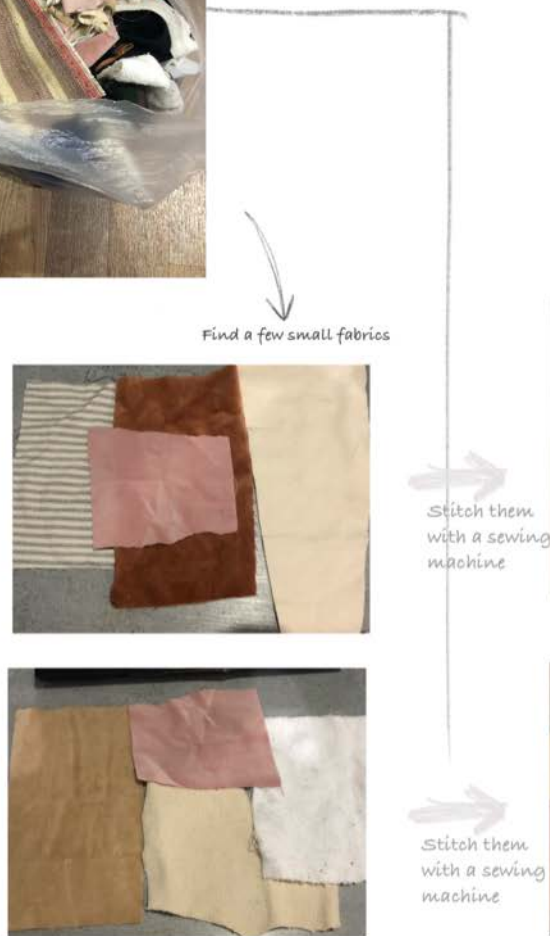

Splice some wasted fabrics to form a new fabric, and then make a bag.
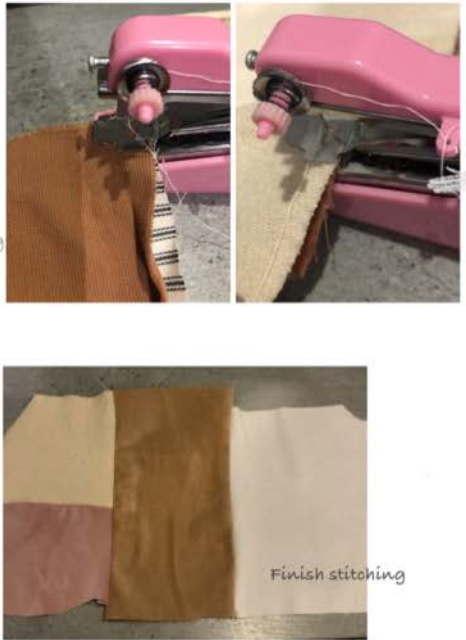

(a)
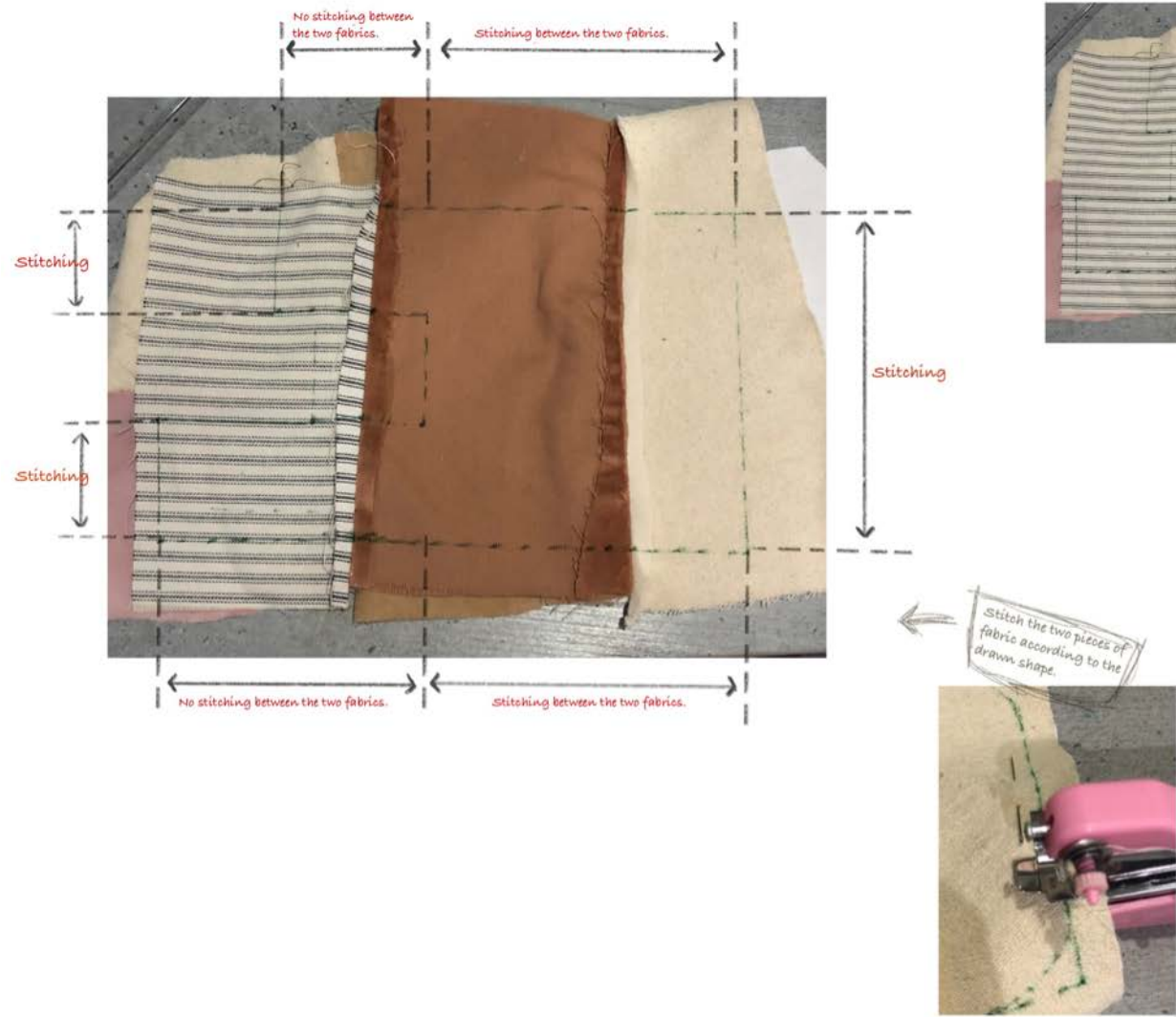

Finish stitching

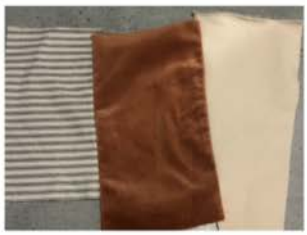

(b) 


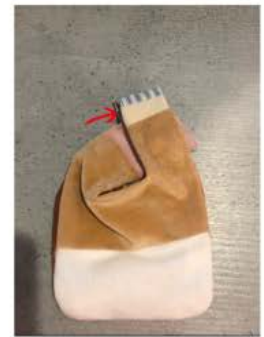

The look of the bag

in hand.

The stitching is complete.

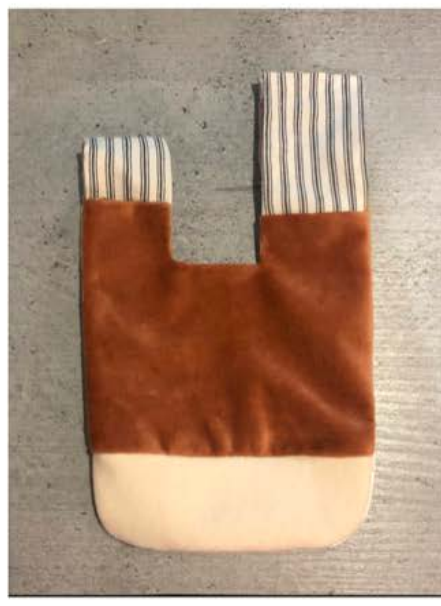

Front

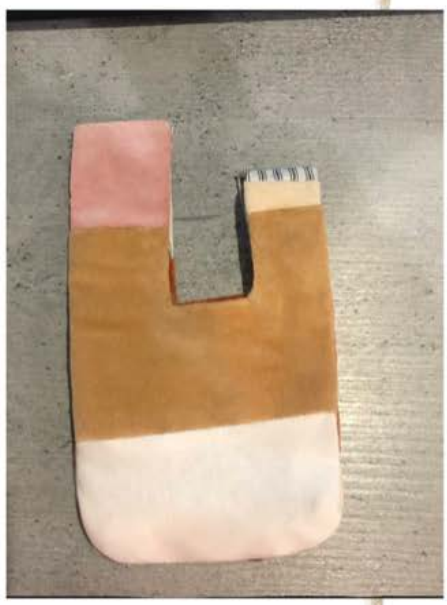

Back
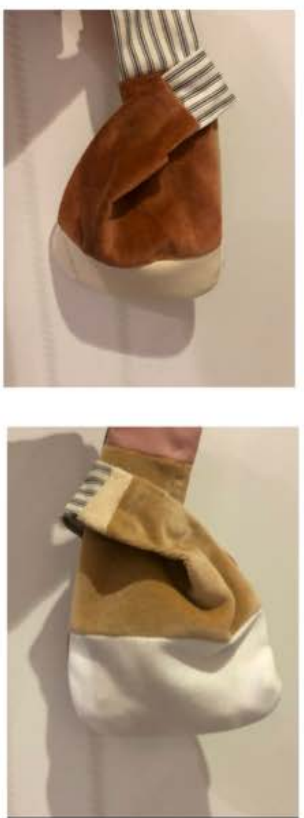

(c)

Figure 22. (a) Stitching process; (b): stitching process; (c): color-blocking bag.

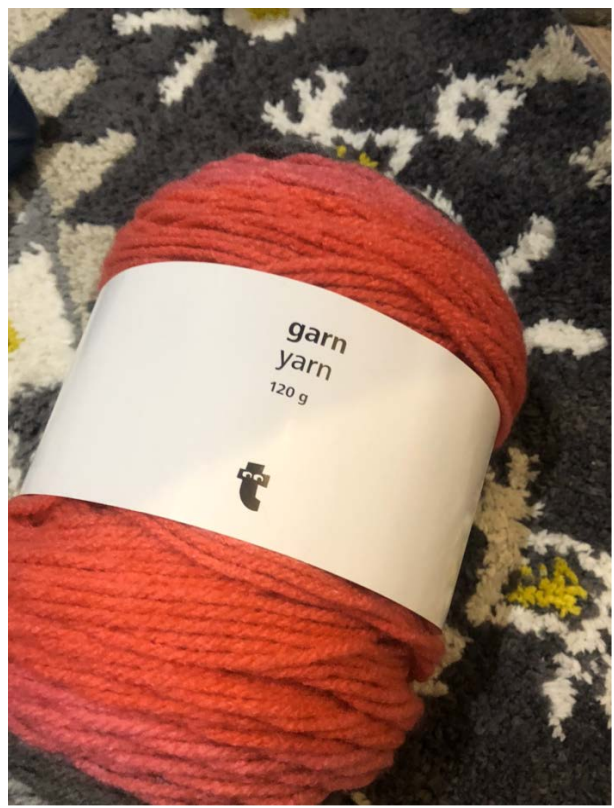

Figure 23. Woolen thread. 


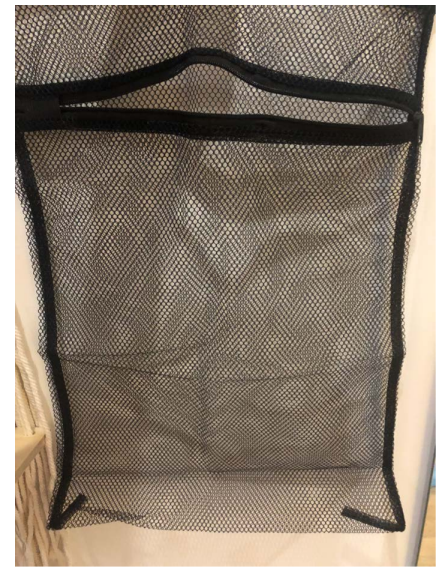

(a)

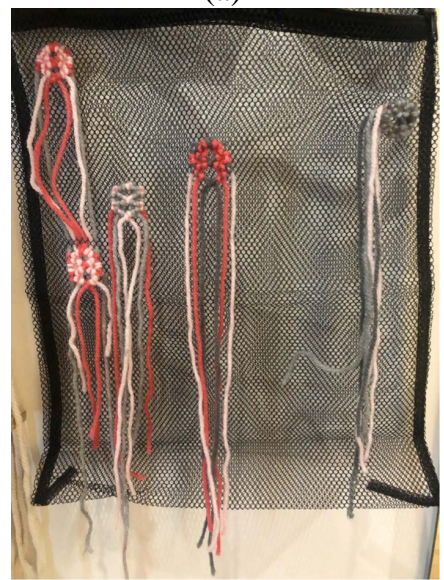

(b)
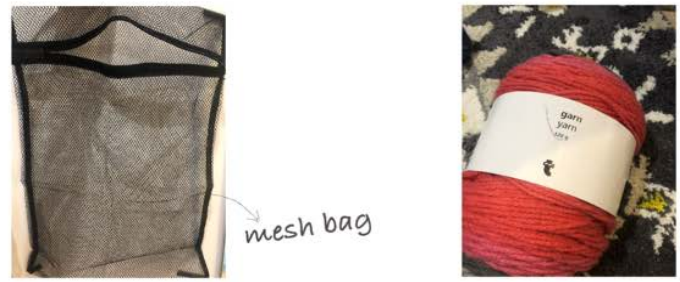

Reuse with mesh bag and yarn to make

a new recycled fabric that can be used on clothing

Put three different
the three grids.
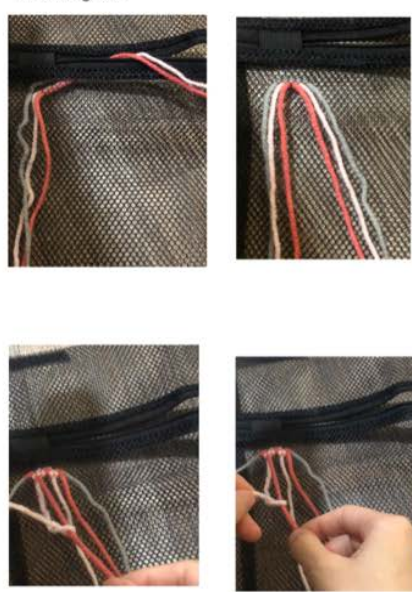

second group

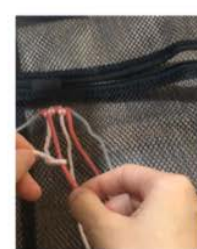

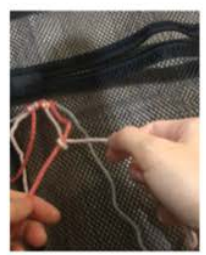
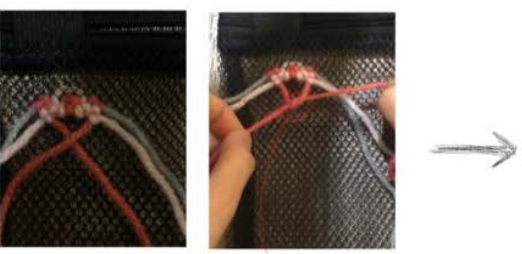

Knotted to fix it
The first group is

completed
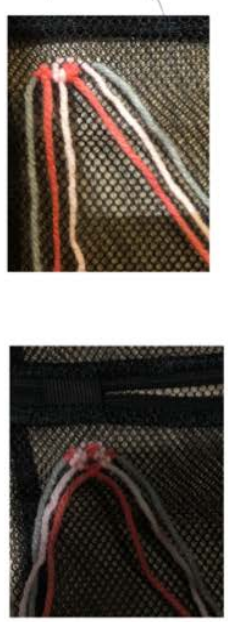

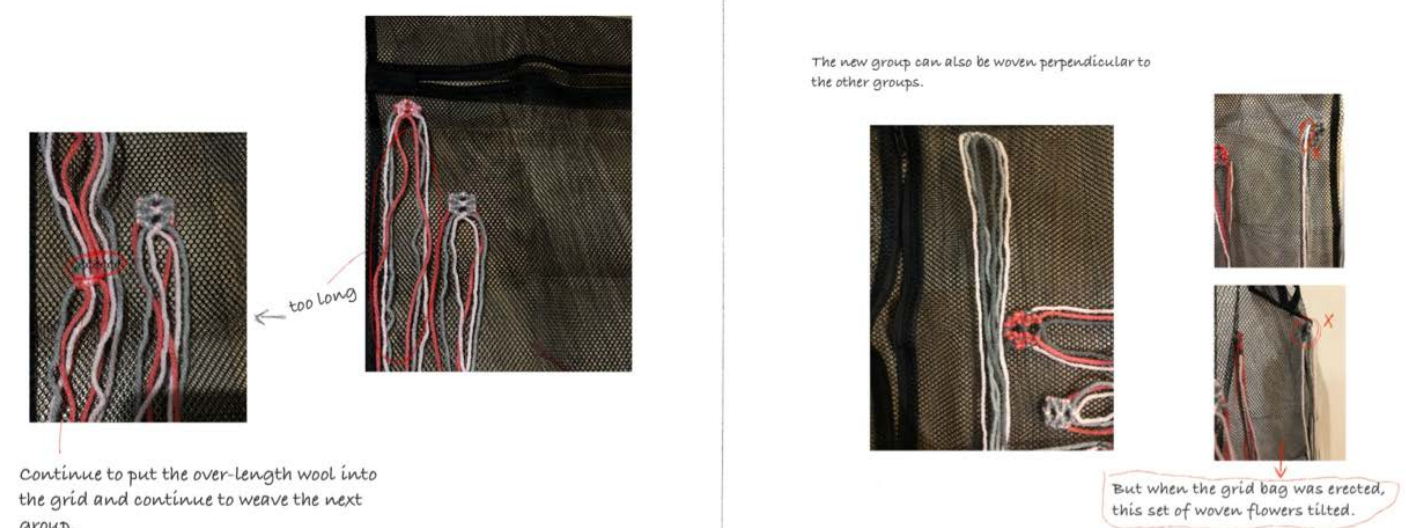

the grid and pontinue over-length wool into

group.

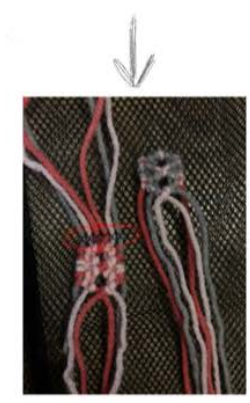

completion of next group

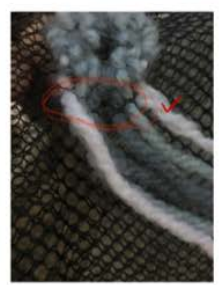

Thread the wool into
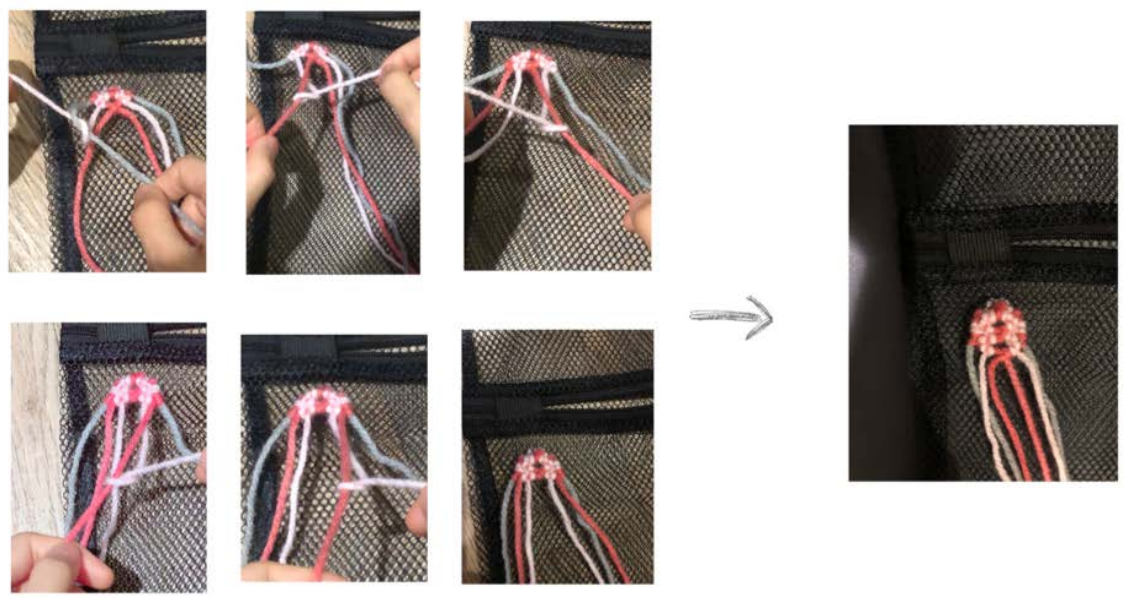

The completion of the first

weave
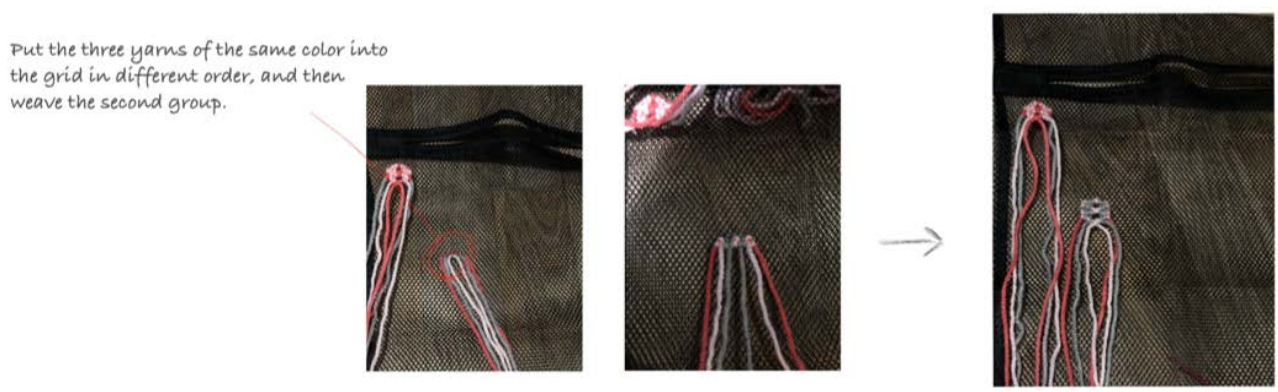

(c)

Figure 24. (a): Mesh bag; (b): mesh bag and woolen thread; (c): making process of combing mesh bag and woolen thread. 

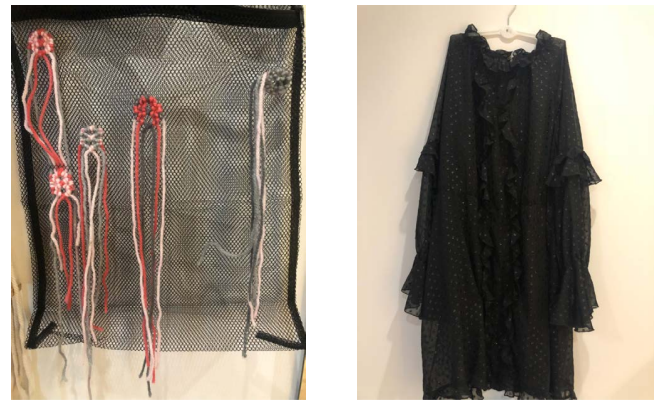

Figure 25. Prepared materials.

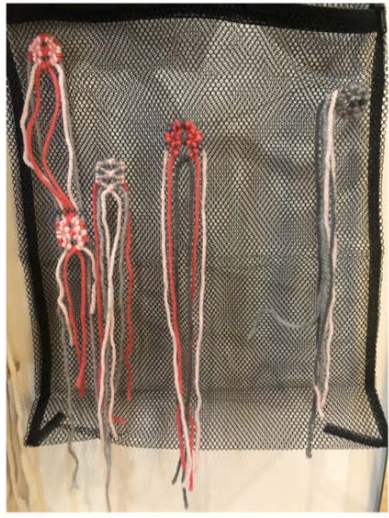

Initial Design

Take pictures of the woven mesh bag and make a initial design, considering how to combine it with waste clothes.

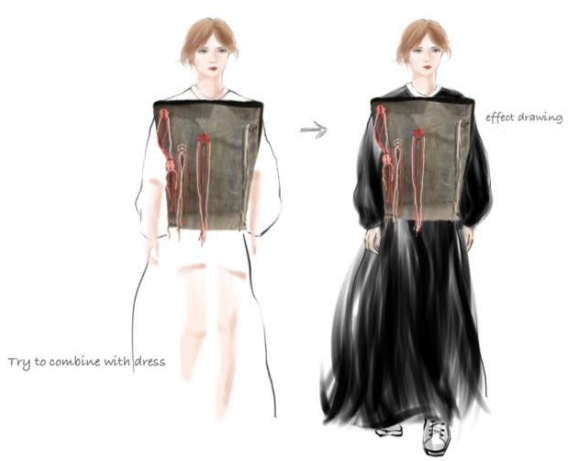

Figure 26. Designed picture.
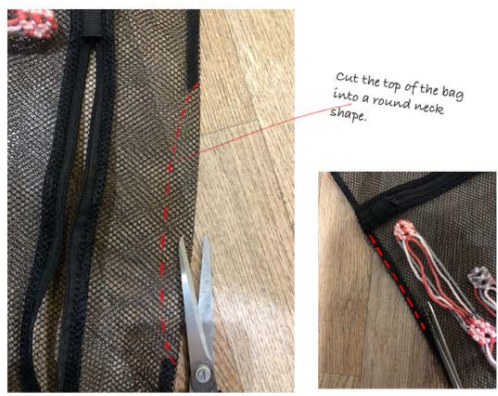

sleeves can be taken out.
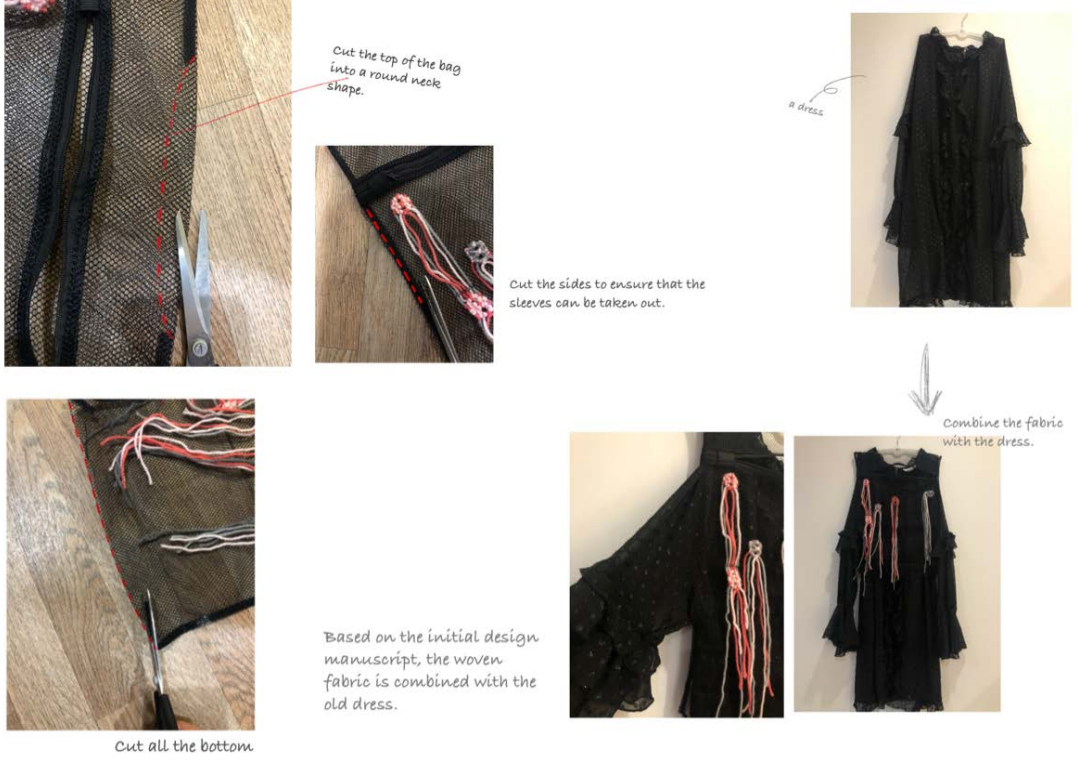

ased on the initial desig manuscript, the woven fabric is combined with the old dress.
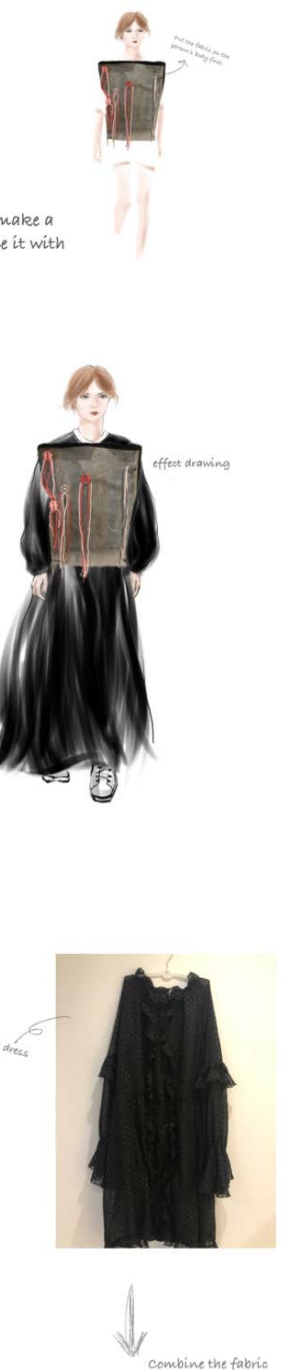

Figure 27. Final designation. 


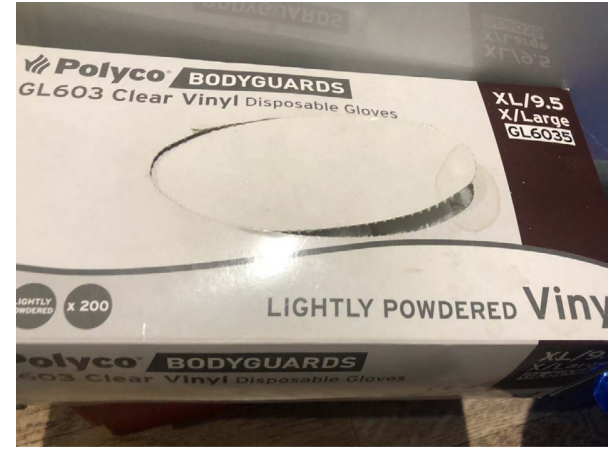

Figure 28. Dispensable gloves in a box.

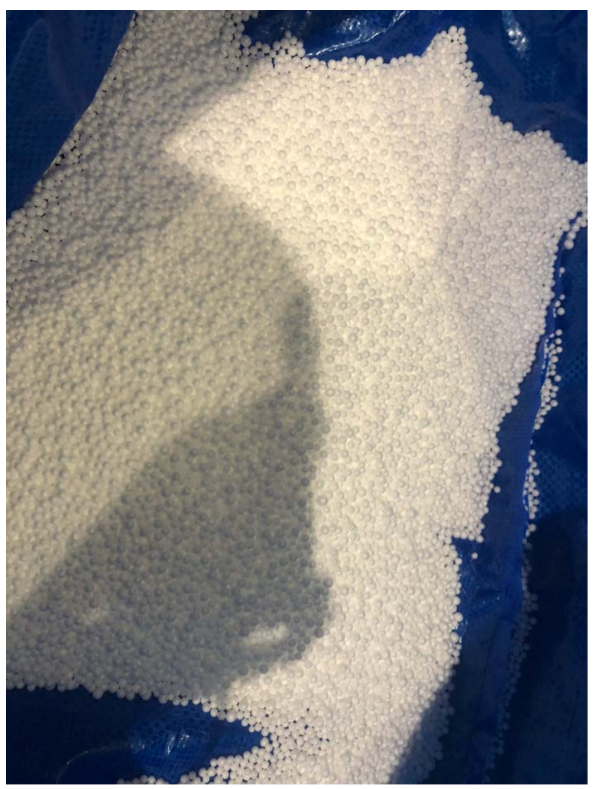

Figure 29. Foam balls.

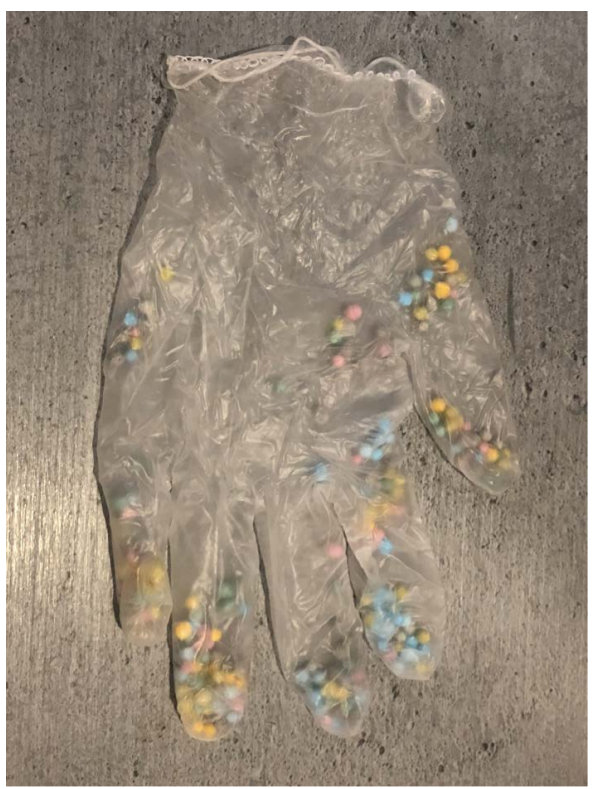

Figure 30. Dispensable glove used. 
Through the combination of waste

products, make some new elements that

can be used in clothing.

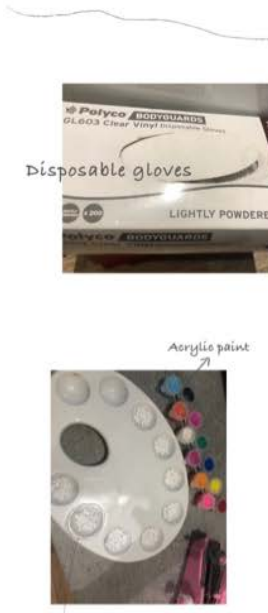

Put these form balls in the palette.
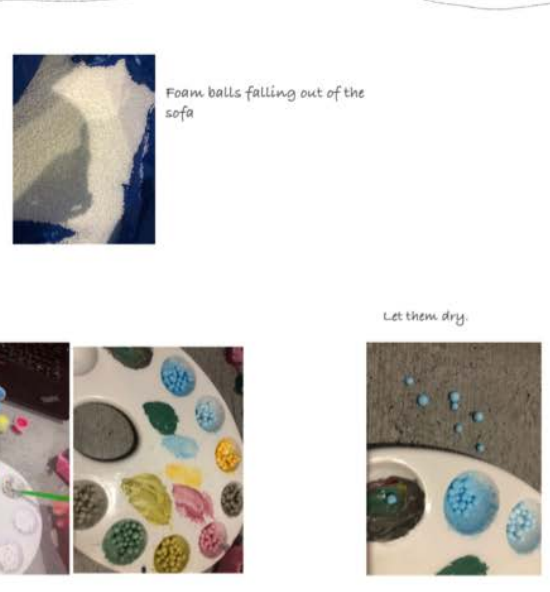

stitch the disposable gloves
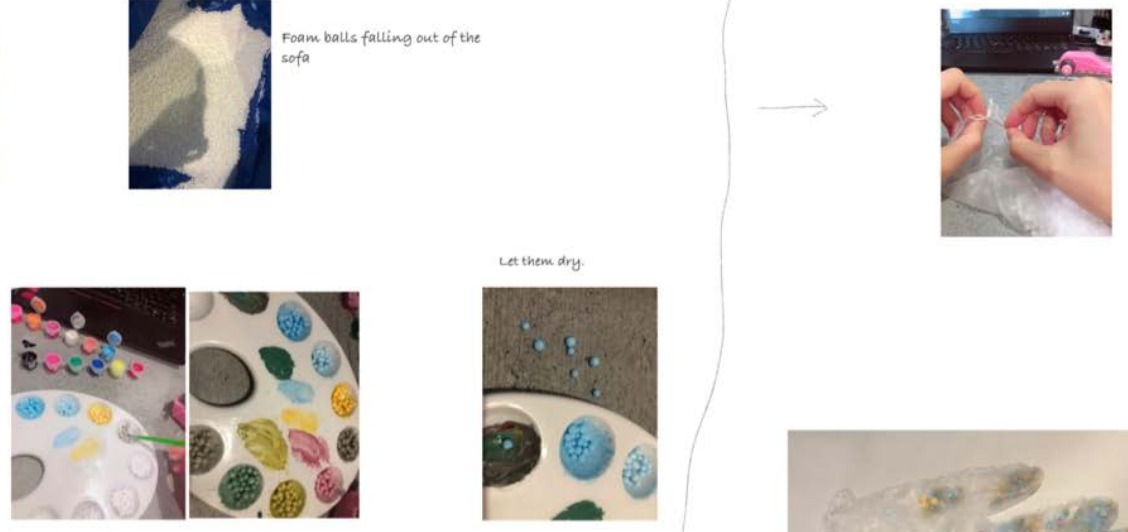

paint them with acrylio paint.

Figure 31. Use disposable gloves and foam balls to combine into a new fabric.
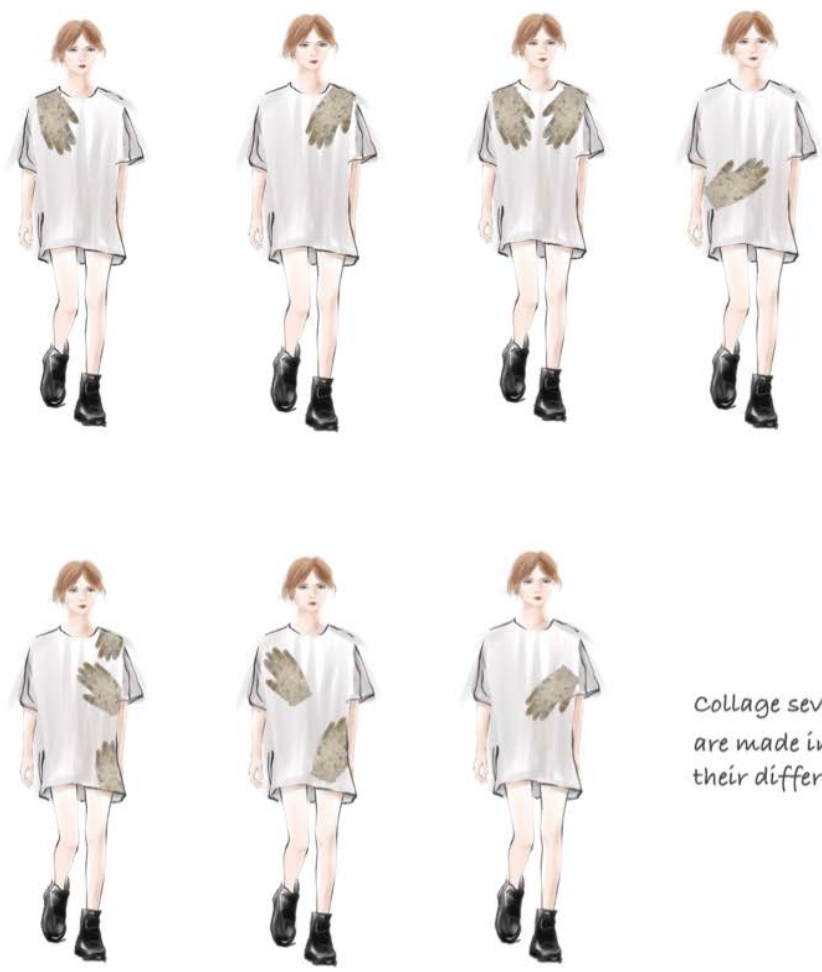

collage several disposable gloves, which are made into new fabrics, then design their different positions on shirts.

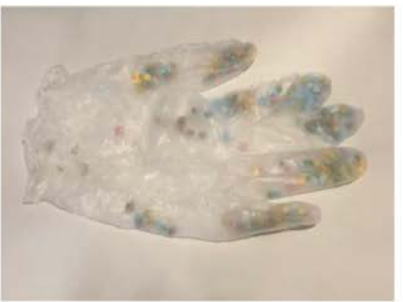

Figure 32. Drawing design process. 


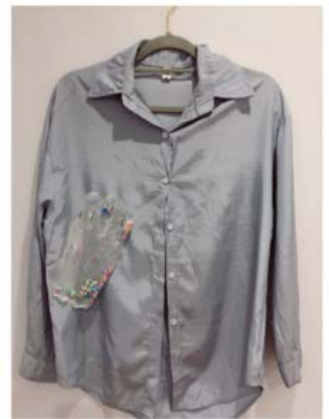

Through the design manuscripts, these gloves are fixed on the shirt that is not worn and placed according to the position on the manuscripts.
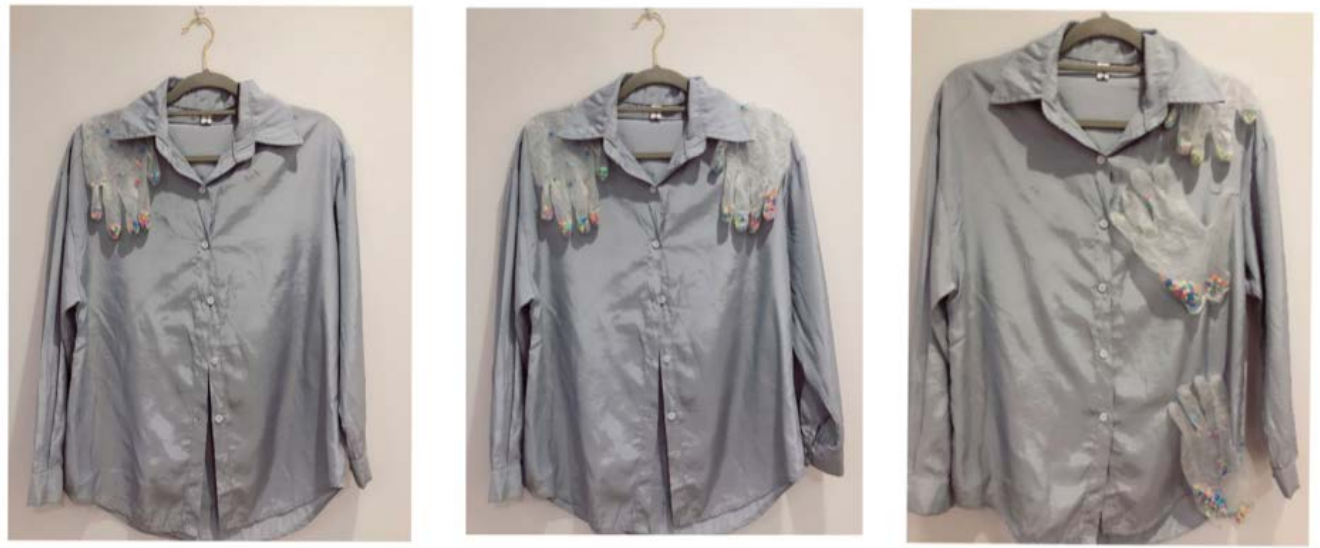

Figure 33. Practical design process.

They choose the suitable fabric and collect the right domestic waste combined into an actual recreated fabric. For example, mesh bags and woolen yarn collected in primary research are ideal candidates for the project.

Stitch different fabrics (see Figure 22(a) \& Figure 22(b)).

It is effortless and familiar for these smaller fabrics to splice them into the fabric with a new color block bag (see Figure 22(c)).

In addition, the household mesh bag is also a kind of usable fabric. It is handwoven in its mesh with woolen thread (see Figure 23), which can weave a new fabric and try its application in clothing (see Figures 24(a)-(c)).

1) Initial Design:

After doing some fabrics reconstruction, then need to further study their combination and connection with clothing, and do some preliminary design (see Figures 25-27).

2) Final Design:

Through the reflection on the practices of both primary and secondary research, the choice of mesh fabric for ready-to-wear garments is relatively limited. In contrast, the recreated fabric of gloves is more feasible.

Disposable gloves and foam balls form the new fabric and clothing combination. The glove is a smaller fabric, which could be designed and used in different positions on the clothes (see Figures 28-33). 


\section{Conclusion}

Due to the heavy environmental pollution of contemporary society (see Appannagari, 2017; Meybeck, 2013; Su, 2014), the clothing industry cannot deny its responsibility. Therefore, reconstruction and recycling are essential for designers and should be given more attention.

Nowadays, consumers who abandoned large amounts of old clothes while chasing new season ones pushed the high-paced fashion industry. As a result, the recycling and reconstruction of clothing and fabrics can effectively solve this problem. However, only solving the waste of clothing cannot fundamentally solve the environmental problem, so combining recreated fabrics with clothing can effectively reduce waste and make the human environment more sustainable.

The designs and selections of reconstruction are also critical. Under certain conditions, designers need to choose fabrics and wastes that can help them truly achieve their design concepts and objectives. The designers also need to integrate them with clothing, achieving actual recycling truly.

\section{Conflicts of Interest}

The author declares no conflicts of interest regarding the publication of this paper.

\section{References}

Appannagari, R. R. (2017). Environmental Pollution Causes and Consequences: A Study. North Asian International Research Journal of Social Science and Humanities, 3, 151-161.

Francois, S. (2019). World Economic Forum: Environment and Natural Resource Security. https://www.weforum.org/videos/environment-and-natural-resource-security

Gam, H. J. (2011). Are Fashion-Conscious Consumers More Likely to Adopt Eco-Friendly Clothing? Journal of Fashion Marketing and Management. An International Journal, 15, 178-193. https://doi.org/10.1108/13612021111132627

James (2020).

https://compareethics.com/9-recycled-and-upcycled-clothing-brands-you-shouldnt-pa ss-in-2018/

Jun, L., \& Yueming, Y. (2015). Research on Form Innovation Design and Implementation of Secondary Reconstruction for Cool Core Fabric. In 2015 Conference on Informatization in Education, Management and Business (IEMB-15) (pp. 1013-1017). Atlantis Press. https://doi.org/10.2991/iemb-15.2015.207

Larsen, A. W. (2011). Evolution of Polynesian Bark Cloth and Factors Influencing Cultural Change. Journal of Anthropological Archaeology, 30, 116-134.

https://doi.org/10.1016/j.jaa.2010.12.004

Libo, N. (2019). Clothing Material. Fabric Creativity-Rebuilding Texture.

Loscialpo, F. (2014). Utopian Clothing: The Futurist and Constructivist Proposals in the Early 1920s. Clothing Cultures, 1, 225-244. https://doi.org/10.1386/cc.1.3.225_1

Mary, E.-S. (2016). The Daily Sew: Reconstructing Garments; What, Why and How. https://static1.squarespace.com/static/582d0d16440243165eb756db/t/5dca24ef92a7e01 852f5eee7/1573528825574/LEARN_Reconstruction_ENG_Nov2019.pdf

Meybeck, M. I. C. H. E. L. (2013). Heavy Metal Contamination in Rivers across the Globe: 
An Indicator of Complex Interactions between Societies and Catchments. Proceedings f H04 Understanding Freshwater Quality Problems in a Changing World, 361, 3-16.

Sass (2017). https://issuu.com/fashionrevolution/docs/fr_zine2_rgb

Sogou Guide (2019). How to Make Clothes from Waste 28.

$\mathrm{Su}$, C. (2014). A Review on Heavy Metal Contamination in the Soil Worldwide: Situation, Impact and Remediation Techniques. Environmental Skeptics and Critics, 3, 24.

WRAP (2012). Redress: The Ecochic Design Award Reconstruction Design Technique. https://modopactua.com/pdf/LEARN_Reconstruction_ENG.pdf

Yueming, Y. (2017). The Discussion of Clothing Form with Geometric Modeling. Advances in Social Science, Education and Humanities Research, 185, 10-12.

\section{Link References}

https: //www.officetimeline.com/gantt-chart-template/powerpoint-gantt-chart-download https: //www.trvst.world/inspiration/turning-plastic-waste-into-clothes/

https://www.fashionrevolution.org/usa-blog/7-fashion-brands-that-are-designing-out-wa ste/

https: //www.needles.jp/

https: //www.raeburndesign.co.uk/ 